\title{
Diagnosis and management of acute lower gastrointestinal bleeding: European Society of Gastrointestinal Endoscopy (ESGE) Guideline
}

Authors

Konstantinos Triantafyllou ${ }^{1}$, Paraskevas Gkolfakis ${ }^{2}$, Ian M. Gralnek ${ }^{3,4}$, Kathryn Oakland ${ }^{\circledR}$, Gianpiero Manes ${ }^{6} \bullet$, Franco Radaelli ${ }^{7}$, Halim Awadie ${ }^{3} \odot$, Marine Camus Duboc ${ }^{8}$, Dimitrios Christodoulou ${ }^{9}$, Evgeny Fedorov ${ }^{10}$, Richard J. Guy $^{11}$, Marcus Hollenbach ${ }^{12} \stackrel{\oplus}{ }$, Mostafa Ibrahim ${ }^{13}$, Ziv Neeman ${ }^{4}$, Daniele Regge ${ }^{14,19}$, Enrique Rodriguez de Santiago ${ }^{15}$, Tony C. Tham ${ }^{16}$, Peter Thelin-Schmidt ${ }^{17}$, Jeanin E. van Hooft ${ }^{18}$

Institutions

1 Hepatogastroenterology Unit, Second Department of Propaedeutic Internal Medicine, Medical School, National and Kapodistrian University of Athens, Attikon University General Hospital, Athens, Greece

2 Department of Gastroenterology, Hepatopancreatology, and Digestive Oncology, CUB Erasme University Hospital, Université Libre de Bruxelles, Brussels, Belgium

3 Institute of Gastroenterology and Hepatology, Emek Medical Center, Afula, Israel

4 Rappaport Faculty of Medicine, Technion-Israel Institute of Technology, Haifa, Israel

5 Digestive Diseases and Renal Department, HCA Healthcare, London, UK

6 Gastroenterology and Endoscopy Unit, ASST Rhodense, Garbagnate Milanese and Rho, Milan, Italy

7 Gastroenterology Department, Valduce Hospital, Como, Italy

8 Gastroenterology Department, Saint-Antoine Hospital, APHP Sorbonne University, Paris, France

9 Division of Gastroenterology, University Hospital \& Faculty of Medicine, School of Health Sciences, University of Ioannina, Ioannina, Greece

10 Department of Gastroenterology, Moscow University Hospital, Pirogov Russia National Research Medical University, Moscow, Russia

11 Department of Emergency General Surgery, Wirral University Teaching Hospital NHS Foundation Trust, Birkenhead, Wirral, UK

12 Medical Department II, Division of Gastroenterology, University of Leipzig Medical Center, Leipzig, Germany

13 Department of Gastroenterology and Hepatology, Theodor Bilharz Research Institute, Cairo, Egypt

14 Radiology Unit, Candiolo Cancer Institute, FPO-IRCCS, Candiolo

15 Department of Gastroenterology and Hepatology, Hospital Universitario Ramón y Cajal, University of
Alcala, Instituto Ramón y Cajal de Investigación Sanitaria (IRYCIS), Spain

16 Division of Gastroenterology, Ulster Hospital, Belfast, Northern Ireland, UK

17 Department of Medicine (Solna), Karolinska Institute and Department of Medicine, Ersta Hospital, Stockholm, Sweden

18 Department of Gastroenterology and Hepatology, Leiden University Medical Center, Leiden, The Netherlands

19 Department of Surgical Sciences, University of Turin, Turin, Italy

published online 1.6 .2021

Bibliography

Endoscopy 2021; 53: 850-868

DOI 10.1055/a-1496-8969

ISSN 0013-726X

(C) 2021. European Society of Gastrointestinal Endoscopy

All rights reserved.

This article is published by Thieme.

Georg Thieme Verlag KG, Rüdigerstraße 14,

70469 Stuttgart, Germany

\# Appendix 1s, Tables 1s-17s

Supplementary material is available under

https://doi.org/10.1055/a-1496-8969

Corresponding author

Konstantinos Triantafyllou, MD PhD, Hepatogastroenterology Unit, Second Department of Propaedeutic Internal Medicine, Medical School, National and Kapodistrian University of Athens, Attikon University General Hospital, 1, Rimini Street, 12462 Athens, Greece

ktriant@med.uoa.gr 


\section{MAIN RECOMMENDATIONS}

1 ESGE recommends that the initial assessment of patients presenting with acute lower gastrointestinal bleeding should include: a history of co-morbidities and medications that promote bleeding; hemodynamic parameters; physical examination (including digital rectal examination); and laboratory markers. A risk score can be used to aid, but should not replace, clinician judgment.

Strong recommendation, low quality evidence.

2 ESGE recommends that, in patients presenting with a selflimited bleed and no adverse clinical features, an Oakland score of $\leq 8$ points can be used to guide the clinician decision to discharge the patient for outpatient investigation. Strong recommendation, moderate quality evidence.

3 ESGE recommends, in hemodynamically stable patients with acute lower gastrointestinal bleeding and no history of cardiovascular disease, a restrictive red blood cell transfusion strategy, with a hemoglobin threshold of $\leq 7 \mathrm{~g} / \mathrm{dL}$ prompting red blood cell transfusion. A post-transfusion target hemoglobin concentration of $7-9 \mathrm{~g} / \mathrm{dL}$ is desirable. Strong recommendation, low quality evidence.

4 ESGE recommends, in hemodynamically stable patients with acute lower gastrointestinal bleeding and a history of acute or chronic cardiovascular disease, a more liberal red blood cell transfusion strategy, with a hemoglobin threshold of $\leq 8 \mathrm{~g} / \mathrm{dL}$ prompting red blood cell transfusion. A posttransfusion target hemoglobin concentration of $\geq 10 \mathrm{~g} / \mathrm{dL}$ is desirable.

Strong recommendation, low quality evidence.

5 ESGE recommends that, in patients with major acute lower gastrointestinal bleeding, colonoscopy should be performed sometime during their hospital stay because there is no high quality evidence that early colonoscopy influences patient outcomes.

Strong recommendation, low quality of evidence.
6 ESGE recommends that patients with hemodynamic instability and suspected ongoing bleeding undergo computed tomography angiography before endoscopic or radiologic treatment to locate the site of bleeding.

Strong recommendation, low quality evidence.

7 ESGE recommends withholding vitamin $\mathrm{K}$ antagonists in patients with major lower gastrointestinal bleeding and correcting their coagulopathy according to the severity of bleeding and their thrombotic risk. In patients with hemodynamic instability, we recommend administering intravenous vitamin $\mathrm{K}$ and four-factor prothrombin complex concentrate (PCC), or fresh frozen plasma if PCC is not available.

Strong recommendation, low quality evidence.

8 ESGE recommends temporarily withholding direct oral anticoagulants at presentation in patients with major lower gastrointestinal bleeding.

Strong recommendation, low quality evidence.

9 ESGE does not recommend withholding aspirin in patients taking low dose aspirin for secondary cardiovascular prevention. If withheld, low dose aspirin should be resumed, preferably within 5 days or even earlier if hemostasis is achieved or there is no further evidence of bleeding. Strong recommendation, moderate quality evidence.

10 ESGE does not recommend routinely discontinuing dual antiplatelet therapy (low dose aspirin and a P2Y12 receptor antagonist) before cardiology consultation. Continuation of the aspirin is recommended, whereas the $\mathrm{P} 2 \mathrm{Y} 12$ receptor antagonist can be continued or temporarily interrupted according to the severity of bleeding and the ischemic risk. If interrupted, the P2Y12 receptor antagonist should be restarted within 5 days, if still indicated.

Strong recommendation, low quality evidence.

\section{SOURCE AND SCOPE}

This Guideline is an official statement of the European Society of Gastrointestinal Endoscopy (ESGE). It provides guidance on the diagnosis and management of acute lower gastrointestinal bleeding. The Grading of Recommendations Assessment, Development, and Evaluation (GRADE) system was adopted to define the strength of recommendations and the quality of evidence.

\section{Introduction}

This European Society of Gastrointestinal Endoscopy (ESGE) Guideline aims to summarize the available evidence and provide guidance regarding the diagnosis and management of acute lower gastrointestinal bleeding (LGIB) focusing on the risk stratification of patients, the role of endoscopy and other modalities (interventional radiology, surgery) ( $\mathbf{F i g . 1}$ ), and on the appropriate management of antithrombotic agents in patients presenting with acute LGIB. All recommendations in this Guideline apply in patients with major LGIB as defined in section 4 of this document. 


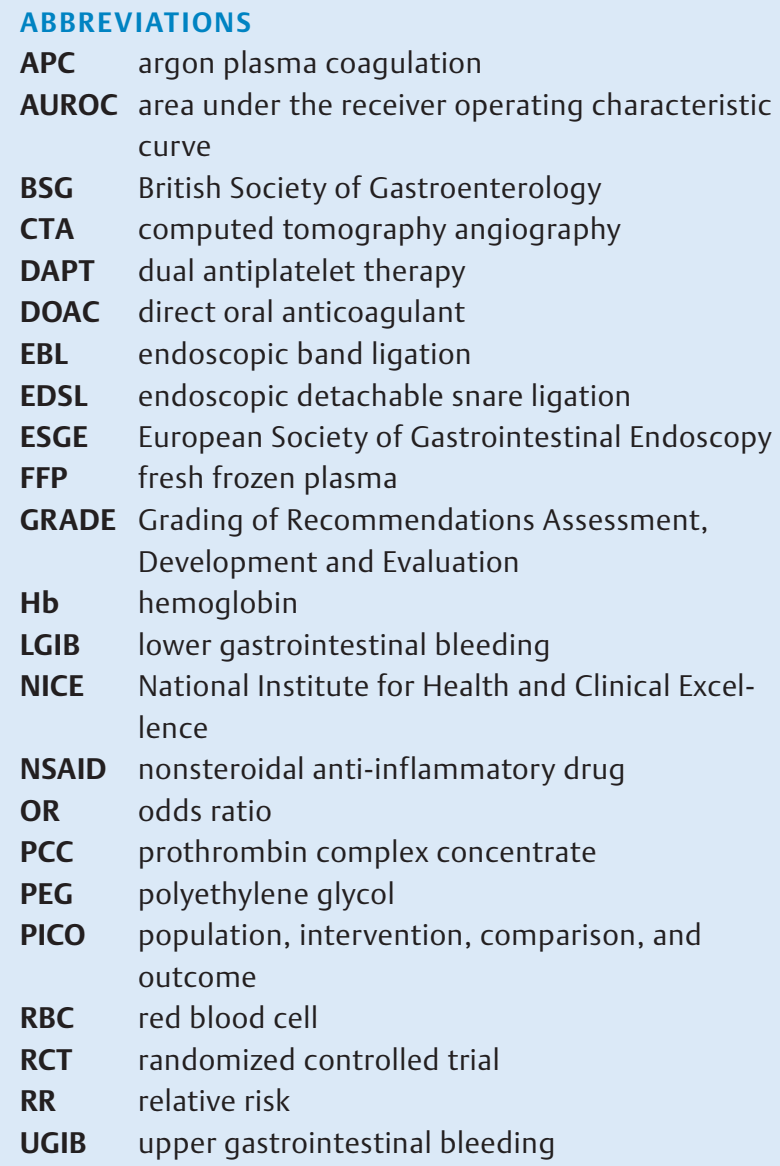

\section{Methods}

The ESGE commissioned this clinical Guideline (ESGE Guideline Committee chair, J.v.H.) and appointed a guideline leader (K.T.). The guideline leader established four task forces each with its own leader (K.O., I.G., G.M., F.R.). Key questions were prepared by the coordinating team (K.T., K.O., I.G., G.M., F.R., P.G.) and divided amongst the four task forces (Appendix $1 \mathrm{~s}$, see online-only Supplementary material). Each task force performed a structured systematic literature search using keywords in English-language articles until August 31, 2020 in Ovid MEDLINE, EMBASE, Google Scholar, and the Cochrane Database of Systematic Reviews. The hierarchy of studies included in this evidence-based guideline was, in decreasing order of evidence level, published systematic reviews/meta-analyses, randomized controlled trials (RCTs), prospective and retrospective observational studies, case series.

Evidence on each key question was summarized in tables (Tables 1s-17s), using the Grading of Recommendations Assessment, Development and Evaluation (GRADE) system, wherever applicable [1]. Grading of the evidence depends on the balance between the benefits and risk or burden of any health intervention. Further details on ESGE guideline development have been previously published [2].

The results of the literature search and answers to the PICO questions were presented to all guideline group members dur- ing two online meetings conducted on September 26 and 27, 2020. Subsequently, drafts were created by each task force leader and distributed between the task force members for revision and online discussion. In November 2020, a full draft prepared by K.T., P.G. and the four task force leaders was sent to all guideline group members. After the agreement of all members had been obtained, the manuscript was reviewed by two independent external reviewers. The manuscript was then sent for further comments to all ESGE member societies and individual members. The final revised manuscript, having been agreed upon by all the authors, was submitted to the journal Endoscopy for publication.

This ESGE Guideline was issued in 2021 and will be considered for update in 2026. Any interim updates will be noted on the ESGE website: http://www.esge.com/esge-guidelines.html.

\section{Definition, epidemiology, and risk factors}

For the purposes of this guideline, the term "lower gastrointestinal bleeding" will be used for any bleeding deriving from a site distal to the ileocecal valve and including the rectum $[3,4]$. The majority of LGIB causes are summarized in $>$ Table $1[4,5]$ and its most common clinical presentation is hematochezia.

Diverticular bleeding is the commonest cause of LGIB with an incidence exceeding $20 \%$ among patients admitted to hospital [6]. The incidence of definitive diverticular bleeding (high risk stigmata at endoscopy or bleeding diverticula on computed tomography angiography [CTA] or classic angiography) was $20 \%$, but increased to $34 \%$ when presumptive diverticular bleeding (diagnosis of diverticular disease with lack of any other evident bleeding source in the endoscopy or complementary work-up) was taken into account [7].

Anorectal diseases are the second most frequent cause of LGIB. Hemorrhoidal bleeding is diagnosed in $12 \%-21 \%$ of patients admitted to hospital with a presenting complaint of LGIB, which is usually small in amount and self-limited [6]. However, massive hemorrhoidal bleeding in elderly patients receiving anticoagulants has been described [8].

Other causes of LGIB include different types of colitis (e.g. ischemic), radiation proctitis, iatrogenic-induced bleeding (e. g. post-polypectomy), vascular malformations (e. g. angioectasias), and colorectal cancer, among others, while no finding was recently reported in $22.8 \%$ of patients with acute LGIB [6].

Different risk factors may trigger LGIB (Table $1 \mathrm{~s}$ ). Alcohol consumption, smoking index $\geq 400$, nonsteroidal anti-inflammatory drugs (NSAIDs), low dose aspirin, and non-aspirin antiplatelet drugs have been identified as independent risk factors for diverticular bleeding (odds ratio $[O R] \geq 1.9$ ) [9], while bilateral diverticular location, nonselective NSAIDs, low dose aspirin, and anticoagulants were associated with an increased risk of diverticular bleeding $(O R \geq 2.23)$ in a case-control study [10]. Finally, a meta-analysis of six studies concluded that both NSAIDs and aspirin significantly increased the relative risk (RR) for diverticular bleeding $(R R \geq 1.73)$ [11].

The incidence of LGIB in patients receiving low dose aspirin in a UK-based, large (more than 199000 new low dose aspirin users; mean follow-up of 5.4 years) population study was 1.22 


\section{Patient presenting with acute LGIB}

Bleeding severity assessment

- History

When did the bleeding start? First episode? Hematochezia? Melena? Recent endoscopy?

- Physical examination (vital signs, cardiopulmonary and abdominal examinations, including DRE) tachycardia? hypotension? syncope? gross blood on DRE? recurrent/ongoing hematochezia?

- Laboratory tests (FBC, serum electrolytes, coagulation tests, type and cross match)

$\downarrow \mathrm{Hb}$ ? $\downarrow$ Albumin? $\uparrow$ INR? $\downarrow$ PLT $\uparrow$ creatinine

- Co-morbidities

Older age? Need for RBC transfusion?

- Concomitant medications

NSAIDs? antiplatelet agents? anticoagulants?

\section{Hemodynamically unstable patient}

- Hemodynamic resuscitation

\section{Diagnosis}

- CTA before any treatment

- Consider UGI endoscopy unless CTA has already located the site of bleeding

- Reserve emergency laparotomy for patients in whom endoscopy and radiology have failed to locate the bleeding site

\section{Treatment}

- Transcatheter embolisation within 60 minutes

- Consider surgery for patients with LGIB due to pathology not amenable to being treated endoscopically or radiologically

\section{Hemodynamically stable patient}

- Consider safe hospital discharge and outpatient evaluation if Oakland score $\leq 8$

- If $\mathrm{Hb} \leq 7 \mathrm{~g} / \mathrm{dL}$, transfuse: target $\mathrm{Hb} 7-9 \mathrm{~g} / \mathrm{dL}$ post transfusion if no CVD

- If $\mathrm{Hb} \leq 8 \mathrm{~g} / \mathrm{dL}$ and CVD present, transfuse: target $\mathrm{Hb} \geq 10 \mathrm{~g} / \mathrm{dL}$

\section{Diagnosis}

Consider colonoscopy as the first diagnostic modality

- Perform sometime during the hospital stay

- Prepare with 4-6 L of PEG-based solution

- NG tube and antiemetics can be used if needed

\section{Treatment}

- Diverticular bleeding: TTS/cap-mounted clip or EBL

- Angioectasia: APC

- Delayed post-polypectomy bleeding:

- Mechanical therapy (TTS/cap-mounted clip or EBL) or

- thermal treatment

- Hemostatic topical agent as salvage treatment

- Fig. 1 Algorithm for assessment, stratification, and management of patients presenting with acute lower gastrointestinal bleeding (LGIB). APC, argon plasma coagulation; CTA, computed tomography angiography; CVD, cardiovascular disease; DRE, digital rectal examination; EBL, endoscopic band ligation; FBC, full blood count; Hb, hemoglobin; INR, international normalized ratio; NG, nasogastric; NSAID, nonsteroidal anti-inflammatory drugs; PEG, polyethylene glycol; PLT, platelets; RBC, red blood cell; TTS, through the scope; UGI, upper gastrointestinal.

(95\% confidence interval [CI] 1.16-1.29) per 1000 personyears, being significantly higher than the incidence rate for upper gastrointestinal bleeding (UGIB) $(0.39$ [95\% CI 0.36-0.43]) [12]. A study from Taiwan showed that low dose aspirin users presented more often with LGIB during their first year of follow-up (0.20\%) [13]. Finally, a meta-analysis of 43 RCTs showed that the oral anticoagulants dabigatran and rivaroxaban were related to an increased risk of major gastrointestinal bleeding compared with conventional anticoagulants (vitamin $K$ antagonists) (OR $\geq 1.27)$; however, the overall risk for LGIB did not differ between the two groups (OR 0.88) [14]. 
- Table 1 Overview of causes of acute lower gastrointestinal bleeding.

\begin{tabular}{|c|c|c|}
\hline \multirow{19}{*}{$\begin{array}{l}\text { Benign } \\
\text { diseases }\end{array}$} & \multicolumn{2}{|c|}{ Diverticular disease } \\
\hline & \multirow{6}{*}{$\begin{array}{l}\text { Anorectal } \\
\text { conditions }\end{array}$} & Hemorrhoids \\
\hline & & Anal fissure \\
\hline & & Solitary rectal ulcer \\
\hline & & Rectal prolapse \\
\hline & & Radiation proctopathy \\
\hline & & Trauma \\
\hline & \multirow{4}{*}{$\begin{array}{l}\text { Vascular } \\
\text { lesions }\end{array}$} & Angioectasias \\
\hline & & Hereditary hemorrhagic telangiectasia \\
\hline & & Dieulafoy's lesion \\
\hline & & Colonic or rectal varices \\
\hline & \multirow[t]{4}{*}{ Colitis } & $\begin{array}{l}\text { Inflammatory bowel disease (ulcerative } \\
\text { colitis, Crohn's disease) }\end{array}$ \\
\hline & & Ischemic colitis \\
\hline & & Infectious colitis \\
\hline & & Undetermined colitis \\
\hline & Polyps & Adenomas, hamartomas \\
\hline & \multirow[t]{2}{*}{ latrogenic } & $\begin{array}{l}\text { Post-endoscopic intervention (polypec- } \\
\text { tomy, EMR, ESD) }\end{array}$ \\
\hline & & Post-surgical \\
\hline & \multicolumn{2}{|c|}{ Chronic anastomotic ulcer } \\
\hline \multirow{3}{*}{$\begin{array}{l}\text { Malignant } \\
\text { diseases }\end{array}$} & \multicolumn{2}{|c|}{ Colorectal cancer } \\
\hline & \multicolumn{2}{|l|}{ Anal cancer } \\
\hline & Metastatic & sive lesions \\
\hline
\end{tabular}

EMR, endoscopic mucosal resection; ESD, endoscopic submucosal dissection.

\section{Triage, risk stratification, and blood transfusion}

\subsection{How should patients with lower gastrointesti- nal bleeding be stratified according to severity?}

\subsection{What should be the initial assessment of patients with lower gastrointestinal bleeding according to the severity of the bleeding?}

\section{RECOMMENDATION}

ESGE recommends that the initial assessment of patients presenting with acute lower gastrointestinal bleeding should include: a history of co-morbidities and medications that promote bleeding; hemodynamic parameters; physical examination (including digital rectal examination); and laboratory markers. A risk score can be used to aid, but should not replace, clinician judgment. Strong recommendation, low quality evidence.
Risk factors for poor LGIB outcome include hemodynamic instability at presentation (tachycardia, hypotension, syncope), ongoing bleeding (gross blood on initial digital rectal examination, recurrent hematochezia), co-morbidities, older age, laboratory findings (hemoglobin, creatinine, albumin, prothrombin time), blood transfusion requirement, and concomitant medication (NSAIDs, antiplatelet agents, and anticoagulants) [158]. When stratifying patients with LGIB according to their severity, their vital signs and the findings of cardiopulmonary, respiratory, abdominal, and digital rectal examination should be included in the initial physical examination.

Although comparatively less well established than in UGIB, risk stratification scores do exist for LGIB. Some have been developed to predict adverse outcomes, including the $A B C$ score [19], Strate score [15], NOBLADS [20], Sengupta score [16], BLEED [17], Birmingham score [21], Severe Acute LGIB (SALGIB) [22] score, and the HAKA score [23]; whilst others have been developed to identify patients at low risk of adverse outcomes: Oakland score [24] and $\mathrm{SHA}_{2} \mathrm{PE}$ [25]. Additionally, scores developed for use in UGIB, such as the Glasgow-Blatchford bleeding score (GBS) [26] and Rockall score [27] have also been shown to have predictive ability in LGIB. No risk score has been directly compared with clinician judgment, therefore the clinical data available at the time of initial patient presentation is the best option to identify patients at high risk for severe bleeding and other adverse outcomes (Table $\mathbf{2 s}$ ).

\subsection{What are the indications to admit a patient with acute lower gastrointestinal bleeding to the hospital?}

\subsection{When can a patient with acute lower gastro- intestinal bleeding be discharged and followed-up as an outpatient?}

\section{RECOMMENDATION}

ESGE suggests that no single risk score should be used in isolation to predict adverse outcomes and determine the need for hospital admission in acute lower gastrointestinal bleeding.

Weak recommendation, low quality evidence.

\section{RECOMMENDATION}

ESGE recommends that, in patients presenting with a selflimited bleed and no adverse clinical features, an Oakland score of $\leq 8$ points can be used to guide the clinician decision to discharge the patient for outpatient investigation. Strong recommendation, moderate quality evidence.

External validation studies of available tools $[15,17,19,20$, $26,28]$ to assess the risk of adverse outcomes in acute LGIB have found that no score reliably identifies all outcomes of interest [24,29]. Oakland et al. assessed risk scores in a prospective study of 2336 LGIB patients: the best predictors of 
Table 2 The performance of the BLEED, NOBLADS, Strate, Glasgow-Blatchford, AIM-65, and ABC scores in the prediction of adverse outcomes in lower gastrointestinal bleeding (LGIB).

\begin{tabular}{|c|c|c|c|c|c|c|}
\hline \multirow[t]{2}{*}{ Score } & \multirow{2}{*}{$\begin{array}{l}\text { Author } \\
\text { (year) }\end{array}$} & \multirow{2}{*}{$\begin{array}{l}\text { External validation } \\
\text { population }\end{array}$} & \multirow{2}{*}{$\begin{array}{l}\text { Population } \\
\text { size }\end{array}$} & Mortality & Rebleeding & RBC transfusion \\
\hline & & & & $\begin{array}{l}\text { Sensitivity } \\
\text { Specificity } \\
\text { AUROC }\end{array}$ & $\begin{array}{l}\text { Sensitivity } \\
\text { Specificity } \\
\text { AUROC }\end{array}$ & $\begin{array}{l}\text { Sensitivity } \\
\text { Specificity } \\
\text { AUROC }\end{array}$ \\
\hline BLEED & $\begin{array}{l}\text { Oakland } \\
\text { (2017) }\end{array}$ & All cases of LGIB, UK & 2336 & $\begin{array}{l}\text { NR } \\
\text { NR } \\
0.68\end{array}$ & $\begin{array}{l}\text { NR } \\
\text { NR } \\
0.63\end{array}$ & $\begin{array}{l}\text { NR } \\
N R \\
0.63\end{array}$ \\
\hline \multirow[t]{2}{*}{ NOBLADS } & $\begin{array}{l}\text { Oakland } \\
\text { (2017) }\end{array}$ & All cases of LGIB, UK & 2336 & $\begin{array}{l}\text { NR } \\
\text { NR } \\
0.72\end{array}$ & $\begin{array}{l}\text { NR } \\
\text { NR } \\
0.62\end{array}$ & $\begin{array}{l}\text { NR } \\
N R \\
0.66\end{array}$ \\
\hline & Aoki (2018) & All cases of LGIB, Japan & 511 & $\begin{array}{l}\text { NR } \\
\text { NR } \\
0.83\end{array}$ & $\begin{array}{l}\text { NR } \\
\text { NR } \\
0.74\end{array}$ & $\begin{array}{l}\text { NR } \\
\text { NR } \\
0.71\end{array}$ \\
\hline Strate & $\begin{array}{l}\text { Oakland } \\
\text { (2017) }\end{array}$ & All cases of LGIB, UK & 2336 & $\begin{array}{l}\text { NR } \\
\text { NR } \\
0.67\end{array}$ & $\begin{array}{l}\text { NR } \\
\text { NR } \\
0.66\end{array}$ & $\begin{array}{l}\text { NR } \\
N R \\
0.73\end{array}$ \\
\hline $\begin{array}{l}\text { Glasgow- } \\
\text { Blatchford }\end{array}$ & $\begin{array}{l}\text { Oakland } \\
\text { (2017) }\end{array}$ & All cases of LGIB, UK & 2336 & $\begin{array}{l}\text { NR } \\
\text { NR } \\
0.73\end{array}$ & $\begin{array}{l}\text { NR } \\
\text { NR } \\
0.74\end{array}$ & $\begin{array}{l}\text { NR } \\
\text { NR } \\
0.86\end{array}$ \\
\hline \multirow[t]{2}{*}{ AIMS-65 } & $\begin{array}{l}\text { Oakland } \\
\text { (2017) }\end{array}$ & All cases of LGIB, UK & 2336 & $\begin{array}{l}\text { NR } \\
\text { NR } \\
0.78\end{array}$ & $\begin{array}{l}\text { NR } \\
\text { NR } \\
0.63\end{array}$ & $\begin{array}{l}\text { NR } \\
\text { NR } \\
0.63\end{array}$ \\
\hline & $\begin{array}{l}\text { Laursen } \\
(2020)\end{array}$ & $\begin{array}{l}\text { All cases of LGIB with } \\
\text { AIMS- } 65 \geq 2 \text {, UK }\end{array}$ & 2336 & $\begin{array}{l}58 \% \\
81 \% \\
0.75\end{array}$ & $\begin{array}{l}\text { NR } \\
N R \\
N R\end{array}$ & $\begin{array}{l}\text { NR } \\
N R \\
N R\end{array}$ \\
\hline$A B C$ & $\begin{array}{l}\text { Laursen } \\
(2020)\end{array}$ & $\begin{array}{l}\text { All cases of LGIB with } \\
A B C \geq 8, \text { UK }\end{array}$ & 2336 & $\begin{array}{l}22 \% \\
97 \% \\
0.84\end{array}$ & $\begin{array}{l}\text { NR } \\
N R \\
N R\end{array}$ & $\begin{array}{l}N R \\
N R \\
N R\end{array}$ \\
\hline
\end{tabular}

mortality, rebleeding, and red blood cell (RBC) transfusion were AIMS-65 (area under the receiver operating characteristic curve [AUROC] 0.78), the Oakland and the GBS (both AUROCs 0.74), and the Oakland score (AUROC 0.92), respectively; however, no score reliably predicted intervention to treat bleeding (AUROCs 0.52-0.65) [24]. - Table 2 summarizes the performance of different available scores for the prediction of mortality, rebleeding, and need for RBC transfusion in patients with LGIB [30]. In a multicenter international study, the $A B C$ score was found to be superior to the AIMS-65 score in predicting mortality (AUROC 0.84 vs. 0.75) [19]. The analysis of other scores and other important adverse outcomes, such as severe bleeding, need for endoscopic hemostasis, embolization, surgery, or RBC transfusion, has been limited to small single-center studies [29,31, 32].

The Oakland [24] ( Table 3 ) and SHA 2 PE [32] scores have been specifically designed to identify low risk patients. The Oakland score was validated in a retrospective study of 38067 patients admitted to 140 hospitals in the USA [33]. It comprises seven variables and has been designed to predict "safe discharge," a composite outcome defined as the absence of inhospital rebleeding, RBC transfusion, therapeutic intervention, in-hospital death, and readmission with subsequent LGIB within 28 days. A score threshold of $\leq 8$ points has a $95 \%$ probability of safe discharge and is the threshold recommended to identify patients for discharge [24, 34]. Therefore, any self-limited LGIB with an Oakland score $\leq 8$ should be considered as minor, and such patients can be considered for early hospital discharge, while all others, presenting with or without hemodynamic instability, should be considered as having a major LGIB.

Oakland et al. assessed the NOBLADS, Strate score, GBS, AIM-65 and pre-endoscopy Rockall score in predicting safe hospital discharge. All scores had an AUROC $<0.65$, except the Strate score (AUROC 0.69), GBS (0.80), and Oakland score (0.84) [24]. The $A B C$ score can be used to identify patients with a low risk of death: a threshold of $\leq 3$ points is associated with a sensitivity of $73 \%$, specificity of $84 \%$, with a mortality rate of $0.6 \%$ [19]. 
- Table 3 The Oakland score for predicting the safe discharge of patients presenting with acute lower gastrointestinal bleeding (LGIB).

\begin{tabular}{|c|c|}
\hline Variable & Score \\
\hline \multicolumn{2}{|l|}{ Age, years } \\
\hline . $<40$ & 0 \\
\hline - 40-69 & 1 \\
\hline.$>70$ & 2 \\
\hline \multicolumn{2}{|l|}{ Sex } \\
\hline - Female & 0 \\
\hline - Male & 1 \\
\hline \multicolumn{2}{|c|}{ Previous LGIB admission } \\
\hline - No & 0 \\
\hline - Yes & 1 \\
\hline \multicolumn{2}{|c|}{ Digital rectal examination findings } \\
\hline - No blood & 0 \\
\hline - Blood & 1 \\
\hline \multicolumn{2}{|c|}{ Heart rate, bpm } \\
\hline . $<70$ & 0 \\
\hline - 70-89 & 1 \\
\hline . 90-109 & 2 \\
\hline . $>110$ & 3 \\
\hline \multicolumn{2}{|c|}{ Systolic blood pressure, $\mathrm{mmHg}$} \\
\hline . 50-89 & 5 \\
\hline . 90-119 & 4 \\
\hline . 120-129 & 3 \\
\hline . 130-159 & 2 \\
\hline$\cdot>160$ & 0 \\
\hline \multicolumn{2}{|c|}{ Hemoglobin, g/dL } \\
\hline - 36-69 & 22 \\
\hline . $70-89$ & 17 \\
\hline . 90-109 & 13 \\
\hline . 110-129 & 8 \\
\hline - 130-159 & 4 \\
\hline " > $>160$ & 0 \\
\hline $\begin{array}{l}\text { bmp, beats per } \\
\text { Adapted from }\end{array}$ & \\
\hline
\end{tabular}

\subsection{When should patients with acute lower gastro- intestinal bleeding be given a blood transfusion?}

\section{RECOMMENDATION}

ESGE recommends, in hemodynamically stable patients with acute lower gastrointestinal bleeding and no history of cardiovascular disease, a restrictive red blood cell transfusion strategy, with a hemoglobin threshold of $\leq 7 \mathrm{~g} / \mathrm{dL}$ prompting red blood cell transfusion. A post-transfusion target hemoglobin concentration of $7-9 \mathrm{~g} / \mathrm{dL}$ is desirable. Strong recommendation, low quality evidence.

\section{RECOMMENDATION}

ESGE recommends, in hemodynamically stable patients with acute lower gastrointestinal bleeding and a history of acute or chronic cardiovascular disease, a more liberal red blood cell transfusion strategy, with a hemoglobin threshold of $\leq 8 \mathrm{~g} / \mathrm{dL}$ prompting red blood cell transfusion. A post-transfusion target hemoglobin concentration of $\geq 10 \mathrm{~g} / \mathrm{dL}$ is desirable.

Strong recommendation, low quality evidence.

A 2015 UK audit of 2528 patients admitted with LGIB found that $26.7 \%$ received $R B C$ transfusion, with $80 \%$ of these transfusions being considered, eventually, as avoidable [35]. The American College of Gastroenterology [36], British Society of Gastroenterology [34], and NICE [37] guidelines, and an international consensus conference [38] have recommended that restrictive transfusion thresholds $(\mathrm{Hb} 7-8 \mathrm{~g} / \mathrm{dl}$ ) should be used in hemodynamically stable patients with acute gastrointestinal bleeding, whilst the threshold should be higher for patients with cardiovascular diseases.

These recommendations are based mainly on evidence deriving from UGIB studies, which have shown that a restrictive blood transfusion strategy is associated with higher survival, lower length of stay, and less RBC transfusion requirement [39-41]. However, a post-hoc analysis of the UK audit of acute LGIB $[35,42]$ found no difference between liberal and restrictive transfusion strategies for the odds of rebleeding or inhospital mortality. Similarly, in both a systematic review of RCTs and an overview of systematic reviews, mortality did not differ between restrictive and liberal transfusion strategies for most of the populations [43,44] (Table 3 s).

On the other hand, elderly patients and patients with cardiovascular disease may have a different response to restrictive transfusion when compared with liberal transfusion. A systematic review and meta-analysis of outcomes in patients with cardiovascular disease in a non-cardiac surgery setting showed that the risk of acute coronary syndrome in patients managed with restrictive compared with liberal transfusion was significantly increased (RR 1.78 [95\% Cl 1.18-2.70]) [45]. Finally, in a metaanalysis of nine RCTs evaluating restrictive vs. liberal transfusion strategies in older adults, the risk of both 30-day and 90day mortality was significantly higher in the restrictive transfu- 
sion group (RR $1.36[95 \% \mathrm{Cl} 1.05-1.74]$ and $\mathrm{RR} 1.45[95 \% \mathrm{Cl}$ 1.05-1.98], respectively) [46]. These findings are particularly relevant to patients presenting with acute LGIB as many of them have either cardiovascular morbidity or are elderly, with a median age of 74 years [6].

\section{Diagnosis and management of lower gastrointestinal bleeding: the role of endoscopy}

\subsection{When should colonoscopy be the first diagnos- tic modality in patients with acute lower gastro- intestinal bleeding?}

\section{RECOMMENDATION}

ESGE recommends that colonoscopy should be the first diagnostic modality for hemodynamically stable patients with acute lower gastrointestinal bleeding because of the therapeutic options it offers.

Strong recommendation, very low-quality evidence.

Colonoscopy allows diagnosis, tissue sampling, and treatment during the same session and is proposed by other current guidelines as the first-line procedure for the majority of patients with acute LGIB $[34,36]$. Colonoscopy is estimated to have a diagnostic accuracy ranging from $42 \%$ to $100 \%$, while hemostatic therapy is performed in $10 \%$ to $63 \%$ of patients $[36,47]$. Unlike CTA, colonoscopy does not require active bleeding for diagnosis and avoids radiation exposure and contrast-induced toxicity.

In a meta-analysis of 22 studies, the overall sensitivity and specificity of CTA in the diagnosis of acute LGIB were $85.2 \%$ (95\% $\mathrm{Cl} 75.5 \%-91.5 \%)$ and $92.1 \%(95 \% \mathrm{Cl} 76.7 \%-97.7 \%)$, respectively [48]. The accuracy of tagged RBC scintigraphy is lower than CTA [49] and varies widely in the literature [36, 48, 49]. Angiography achieves a high rate of immediate hemostasis ( $86 \%-100 \%)$, but is usually reserved as a second-line procedure owing to its invasiveness and rate of adverse events ( $0 \%-60 \%)$ [50].

An RCT by Green et al. compared urgent colonoscopy $(<8$ hours) to a standard protocol that included tagged RBC scintigraphy, followed by visceral angiography when positive, or elective colonoscopy when negative [51]. A definitive source of bleeding was found more often in the urgent colonoscopy group, but the two approaches did not differ in safety, rebleeding, mortality, or transfusion requirements. Early colonoscopy had a significantly higher diagnostic yield ( $85 \%$ vs. $45 \%$; $P=$ 0.005 ) and was associated with shorter length of stay and lower transfusion requirements compared with early radiographic procedures in a retrospective study [47].

Moreover, a recent systematic review compared the diagnostic and therapeutic yields of endoscopy, CTA, and angiography [49]. Among the included studies that compared CTA with tagged RBC scintigraphy, one study demonstrated a higher diagnostic yield for CTA, while the other two reported no dif- ference. A lack of studies precluded the performance of analyses of colonoscopy vs. CTA and colonoscopy vs. first-line angiography.

Clerc et al. found that active bleeding was identified significantly more often with CTA compared with lower gastrointestinal endoscopy (31\% vs. $15 \%$; $P=0.03$ ) [52], whereas Lee et al. reported a similar yield for both modalities [53]. Miyakuni et al. performed a nationwide study in Japan selecting patients with severe LGIB who underwent angiography or urgent colonoscopy within 1 day of admission [54]. After propensity score matching, in-hospital mortality was similar (RR $1.14[95 \% \mathrm{Cl}$ 0.95-1.36]), but the need for surgery within 1 day was lower in the angiography group ( $\mathrm{RR} 0.44$ [95\% Cl 0.29-0.67]).

None of the reviewed studies reported a cost-benefit analysis or showed a significant difference in rebleeding rates, adverse events, 30-day mortality, 30-day surgery rate, hospital length of stay, or transfusion requirements (Tables $4 s-6 s$ ).

To conclude, low quality evidence indicates that CTA and colonoscopy have comparable diagnostic yields and safety profiles. Colonoscopy has the advantage of allowing diagnosis and treatment simultaneously, whereas CTA does not require bowel preparation and might be preferred for selected patients with severe LGIB.

\subsection{What is the appropriate timing for colonoscopy in patients with acute lower gastrointestinal bleed- ing?}

\section{RECOMMENDATION}

ESGE recommends that, in patients with major acute lower gastrointestinal bleeding, colonoscopy should be performed sometime during their hospital stay because there is no high quality evidence that early colonoscopy influences patient outcomes.

Strong recommendation, low quality evidence.

Available evidence comparing early vs. elective colonoscopy in the management of patients with acute LGIB consists of seven systematic reviews with meta-analyses [55-61], four RCTs [51,62-64], and 16 observational studies [65-80] (Table $7 \mathrm{~s})$. Patients with "minor" LGIB managed as outpatients and patients with an UGIB source were excluded from the RCTs $[51,62-64]$ and most of the observational studies $[66,67,69$, 71-78]. Early or urgent colonoscopy was defined as a colonoscopy performed within 24 hours of presentation in most studies [62-64,65-78]. In RCTs, delayed or elective colonoscopy was defined as that performed between 24 hours and 96 hours from the time of hospital admission [51,62-64].

Two recent meta-analyses of observational studies suggested that early colonoscopy reduces all-cause mortality (OR 0.86 [95\% Cl $0.75-0.98]$ ), the need for surgery (OR 0.52 [0.42$0.64]$ ), blood transfusion requirements (OR 0.81 [0.75-0.87]), and hospital length of stay (mean difference -1.7 days), with no significant differences in terms of rebleeding, identification of the source of bleeding, adverse events, or need for endoscopic therapy or interventional radiology $[55,56]$. One RCT also 
found that early colonoscopy was associated with shorter hospital length of stay, but with an increased rate of recurrent bleeding [64], while another RCT revealed that a definitive source of bleeding was more often detected in the urgent colonoscopy group [51].

However, two RCTs did not show any significant differences in the clinical outcomes between early and elective colonoscopy $[62,63]$. Similarly, three meta-analyses that included the four available RCTs did not show any differences regarding rebleeding, mortality, need for additional therapy, length of stay, transfusion requirements, or any other clinical outcome [55-57]. Moreover, subgroup analyses assessing colonoscopy performed within 12 hours from the time of hospital admission and a post-hoc meta-regression intended to determine the impact of hemodynamic instability on clinical outcomes did not find any differences between the groups $[55,57]$.

We considered the certainty of evidence to be low, despite the significant number of studies evaluating the appropriate timing of colonoscopy. All but one [80] of the observational studies were retrospective [65-79], and the definitions and selection criteria were heterogeneous. All RCTs were nonblinded, with some concerns regarding bias (Tables $7 \mathrm{~s}$ and $8 \mathrm{~s}$ ), and two trials were terminated before reaching the pre-planned sample size $[51,63]$. The low number of RCTs and their limited sample sizes led to wide confidence intervals for all outcomes assessed in the meta-analyses and impeded accurate evaluation of publication bias. Finally, moderate to high heterogeneity was found for the pooled data of hospital length of stay and units of blood transfused, altogether leading to imprecision, inconsistency, and uncertain risk of publication bias in the available evidence (Table $8 \mathbf{s}$ ).

To conclude, studies comparing early ( $<24$ hours) vs. delayed (>24 hours) colonoscopy have focused on patients with major acute LGIB in whom colonoscopy was performed during hospitalization. Retrospective data suggest that early colonoscopy may reduce all-cause mortality, the need for surgery, blood transfusion requirements, and hospital length of stay. However, meta-analyses of the RCTs have not confirmed these findings and suggest that both groups have similar clinical outcomes. It remains unclear whether selected acute LGIB patients could benefit from early colonoscopy.

\subsection{Is there a role for unprepped sigmoidoscopy/ colonoscopy in patients presenting with acute lower gastrointestinal bleeding?}

\section{RECOMMENDATION}

ESGE does not recommend unprepped lower gastrointestinal endoscopy (e.g. colonoscopy, sigmoidoscopy) in patients with acute lower gastrointestinal bleeding. Strong recommendation, low quality evidence.

Comparative studies on colonoscopy with and without bowel cleansing in acute LGIB patients are lacking (Table 9s). Current guidelines recommend that colonoscopy should only be performed following adequate bowel preparation [34,36]. Two recent prospective cohort studies in patients with severe LGIB reported the use of "hydro flush colonoscopy" in 12 and 33 patients, respectively $[81,82]$, where colonoscopy was performed after a tap-water enema and the bowel was further cleansed using water or polyethylene glycol (PEG) solution delivered by a water-jet pump and suction during colonoscopy. The bleeding source in many cases of acute LGIB is located proximal to the rectum and sigmoid colon [82,83]; complete colonoscopy should therefore be the aim. However, in cases where CTA has identified a bleeding source in the rectum or sigmoid colon, flexible sigmoidoscopy can be considered.

\subsection{Should upper gastrointestinal endoscopy be performed in patients presenting with acute lower gastrointestinal bleeding?}

\section{RECOMMENDATION}

ESGE recommends that upper gastrointestinal endoscopy be performed in patients presenting with acute lower gastrointestinal bleeding and hemodynamic instability unless computed tomography angiography has already been performed showing a definitive bleeding source in the lower gastrointestinal tract.

Strong recommendation, low quality evidence.

There are no studies comparing upper GI endoscopy vs. no upper $\mathrm{Gl}$ endoscopy in patients with acute LGIB (Table 10 s). Overall, in $8 \%-9 \%$ of patients presenting with LGIB, the source of bleeding is found in the upper GI tract $[6,84]$, whereas in patients with severe hematochezia and hemodynamic instability up to $15 \%$ have an upper bleeding source $[63,85]$. A past medical history of portal hypertension, peptic ulcer, and antiplatelet medication are known risk factors for UGIB $[63,85,86]$. An elevated blood urea/creatinine ratio $(>30)$ has also been found to be indicative of UGIB [86]. The British Society of Gastroenterology (BSG) recommends that an upper GI endoscopy should be performed immediately if no source is identified by initial CTA, while gastroscopy may be the first investigation if the patient stabilizes after initial hemodynamic resuscitation [34]. Similarly, the American College of Gastroenterology recommends upper Gl endoscopy be performed in patients with hematochezia and hemodynamic instability [36].

\subsection{In patients with acute lower gastrointestinal bleeding undergoing colonoscopy, what is the recommended bowel preparation?}

\section{RECOMMENDATION}

ESGE suggests bowel preparation using large volume (4-6L) PEG-based solution. Use of a nasogastric tube combined with an antiemetic agent may facilitate bowel preparation in patients who are intolerant of oral intake. Strong recommendation, moderate quality evidence. 
Adequate preparation of the colon in the setting of acute LGIB facilitates endoscopic visualization, diagnosis, and treatment, and may reduce the risk of bowel perforation. The available data are mostly from studies on acute LGIB using large volume bowel preparation (4-6L of PEG solution within 3-4 hours), with colonoscopy performed within 1-2 hours of the completion of bowel preparation [51, 63, 74, 87] (Table 11 s).

The use of lower volume or alternative colon preparation solutions in the setting of LGIB has not been specifically addressed, but preliminary data appear encouraging [88-90]. A prospective study [91] used $2 \mathrm{~L}$ of PEG solution added to the water-jet tank, starting from the left side of the colon up to the cecum, in elderly patients $(n=33)$. The mean Boston Bowel Preparation Scores during scope insertion and withdrawal were 2.6 and 7.2, respectively; the mean (standard deviation) withdrawal time exceeded the insertion time (28.7 [6.9] minutes vs. 17.1 [4.9] minutes), and the source of bleeding was found in $90.9 \%$ of patients.

In studies of urgent colonoscopy, one-third of patients required a nasogastric tube to facilitate rapid bowel preparation [87]; therefore, a nasogastric tube can be placed to facilitate this process as long as the risk of aspiration is low. Few studies have addressed bowel preparation-related adverse events in acute LGIB. In an age- and sex-matched controlled retrospective study $(n=161)$ using PEG solution or enema for those who could not completely consume the PEG solution, 16 LGIB patients ( $9 \%$ ) experienced an adverse event ( $7 \%$ hypotension, $2 \%$ vomiting) [92].

\subsection{What are the endoscopic hemostasis treatments for acute lower gastrointestinal bleeding?}

The summary of evidence is available in Table $12 \mathrm{~s}$.

\subsubsection{Diverticular bleeding}

\section{RECOMMENDATION}

ESGE suggests mechanical therapy (e.g. through-thescope/cap-mounted clip or endoscopic band ligation) as the preferred treatment for diverticular hemorrhage. Weak recommendation, moderate quality evidence.

Endoscopic treatment for diverticular bleeding has typically included thermal coagulation, endoscopic clipping (throughthe-scope or cap-mounted), endoscopic band ligation (EBL), ligation using an endoscopic detachable snare (EDSL), and administration of epinephrine local injection. Owing to the lack of strong, clear evidence on which hemostasis modality is more effective and/or safer, recommendations depend on a combination of case reports, case series, and prospective and retrospective studies, rather than RCTs and systematic reviews.

5.6.1.1 Injection/thermal contact therapy Injection therapy is used in conjunction with other types of therapy, such as thermal contact methods. Reports have shown their effectiveness for diverticular bleeding $[87,93]$. Thermal con- tact therapies include heater probe therapy and bipolar coagulation, with or without adrenalin injection $[51,87,93]$. However, thermal therapy poses the risk of perforation owing to the thin wall of the colon. Injection of epinephrine alone should not be used as definitive hemostasis therapy.

5.6.1.2 Endoscopic clipping Endoscopic clipping is the method used most often and typically poses less risk of tissue injury. The through-the-scope method of clipping has been the recommendation in previous guidelines [34,36].

5.6.1.3 Endoscopic ligation An historical control study done by Okamoto et al. showed EBL to be superior to clipping, based on its significantly lower rebleeding rates after 1 year of follow-up for patients with bleeding colonic diverticula $(P<$ 0.01 ) [94]. A recent systematic review and meta-analysis compared several endoscopic modalities, including ligation therapy, coagulation, and clipping, in patients with colonic diverticular bleeding. The results suggested that ligation therapy was more effective compared with clipping, in terms of avoiding transcatheter arterial embolization or surgery. However, there were no significant differences in the rates of initial hemostasis and early rebleeding ( $\leq 30$ day) between the coagulation ( $n=$ $33)$, clipping $(n=192)$, and ligation groups $(n=156)$. Pooled analysis showed that the efficacy of band ligation to treat diverticular bleeding was up to $99 \%(95 \% \mathrm{Cl} 95 \%-100 \%)$, with the early recurrent bleeding rate being $9 \%$ (95\%Cl 4\%-15\%) [95].

A recently published review on treatment trends for colonic diverticular bleeding in Japan, which assessed five studies $(\mathrm{n}=$ 510), concluded that EBL is ultimately superior to endoscopic clipping in terms of short- and long-term rebleeding rates and that the proportion of patients needing transcatheter arterial embolization or surgery after EBL is significantly lower than that for patients who underwent endoscopic clipping [96].

While EBL is considered safe and effective [97-99], there have been reports suggesting that EBL carries the risk of serious complications, such as delayed perforation, especially for rightsided lesions [100-103].

5.6.1.4 Endoscopic detachable snare ligation EDSL has also been used to ligate a bleeding diverticulum, similarly to endoscopic band ligation. In a retrospective study, sustained hemostasis was achieved in $7 / 8$ patients $(88 \%)$, with early rebleeding occurring in one patient [104].

5.6.1.5 Hemostatic topical agents Only small studies and case series have evaluated the efficacy and safety of hemostatic topical agents in the treatment of LGIB. In a multicenter prospective study, the EndoClot polysaccharide hemostatic system (EndoClot Plus Inc., Santa Clara, California, USA) was used to treat diverticular bleeding; successful hemostasis was achieved in $83 \%$ of the patients, while the remaining two cases (17\%) rebled secondary to malignancy and a cecal ischemic ulcer [105]. A systematic review by Chen et al. [106] and two small studies $[107,108]$ also described encouraging results for Hemospray (Cook Medical, Bloomington, Indiana, USA) in cases of actively bleeding LGIB lesions. 


\subsubsection{Angioectasia}

\section{RECOMMENDATION}

ESGE recommends treatment of bleeding angioectasia using argon plasma coagulation.

Strong recommendation, low quality evidence.

Argon plasma coagulation (APC) is considered the treatment of choice for angioectasia in the upper and lower gastrointestinal tract because it is associated with lower complication rates and less need for RBC transfusion [109-112]; however, comparative studies are lacking. Injection of a saline-adrenaline solution prior to APC is suggested when treating right-sided colonic lesions, which present a higher risk for perforation [111]. The optimal settings in terms of thermal effect intensity, gas flow, and duration of the application depend on the site and size of the area that is being treated, but typically the power ranges from $20-60 \mathrm{~W}$ and the gas flow rate from $1-2.5 \mathrm{~L} / \mathrm{min}$ ute [109-112].

\subsubsection{Delayed post-polypectomy bleeding}

\section{RECOMMENDATION}

ESGE recommends the use of mechanical therapy (e.g. through-the-scope/cap-mounted clips) and/or contact thermal coagulation as the primary treatment options of delayed post-polypectomy bleeding.

Strong recommendation, low quality evidence.

\section{RECOMMENDATION}

ESGE suggests that hemostatic topical agents be used as a secondary treatment option (e.g. rescue therapy) in cases of inadequate/failed hemostasis with ongoing bleeding.

Weak recommendation, low quality evidence.

The modality used most often to treat delayed post-polypectomy bleeding is through-the-scope clips; however, the use of novel modalities, such as topical hemostatic agents and capmounted clips, has also been reported [113]. Through-thescope clips achieve successful hemostasis in most patients, but evidence is based on clinical experience [113-115]. Treatment using bipolar coagulation, and non-contact coagulation therapy with APC have also been reported [116]. Regarding hemostatic topical agents, a prospective multicenter study of patients with active LGIB $(n=50)$ showed that hemostatic powder, as either monotherapy, combination therapy, or rescue therapy, successfully induced hemostasis in $98 \%$ of the patients; however, five patients (10\%) experienced recurrent bleeding within 30 days [117].
6 Diagnosis and treatment of lower gastrointestinal bleeding: the role of interventional radiology and surgery

\subsection{When should computed tomography angio- graphy be the initial diagnostic modality in patients presenting with acute lower gastrointestinal bleeding?}

\section{RECOMMENDATION}

ESGE recommends that patients with hemodynamic instability and suspected ongoing bleeding undergo computed tomography angiography before endoscopic or radiologic treatment to locate the site of bleeding. Strong recommendation, low quality evidence.

\section{RECOMMENDATION}

ESGE does not recommend red blood cell scintigraphy in the setting of acute lower gastrointestinal bleeding because of its limited accuracy in identifying the location of the bleeding site and logistical constraints.

Strong recommendation, low quality evidence.

No RCT has been published on the accuracy of CTA in detecting LGIB. Retrospective clinical studies report the sensitivity and specificity of CTA for LGIB to be $79 \%-95 \%$ and $95 \%-100 \%$, respectively $[118,119]$. If extravasation of contrast agent is detected at CTA, patients can then undergo angiography and selective mesenteric embolization. Among 20 patients with LGIB, CTA was positive in $9 / 13$ patients (69.2\%) who were hemodynamically unstable and only in $1 / 7$ of the patients (14.3\%) who were hemodynamically stable [120].

Diverticular bleeding is diagnosed more often in patients undergoing CTA prior to endoscopic examination than in those not undergoing CTA (35.7\% vs. $20.6 \%$ ) [121]. Furthermore, precise identification of the bleeding diverticulum is significantly higher in patients with extravasation observed on CTA than in those without this ( $68 \%$ vs. $20 \%$; $P<0.001)$ [122]. Three studies in patients undergoing either CTA or RBC scintigraphy prior to selective angiography did not detect any difference in the incidence of contrast-induced nephropathy between the two diagnostic approaches [123-125]. Recently, Zink et al. demonstrated that CTA and RBC scintigraphy had similar sensitivities in terms of LGIB detection (85.2\% vs. 94.4\%) [124]. However, CTA had a positive correlation with catheter-guided angiography compared with RBC scintigraphy (67.7\% vs. $29.3 \%$ ). Jacovides et al. reported equivalent sensitivity and specificity of RBC scintigraphy and CTA, but the bleeding site located by CTA was more precise and consistent with the angiography findings [123]. Similarly, Feuerstein et al. showed that CTA located the site of LGIB more often compared with RBC scintigraphy (53\% vs. 30\%) [126]. Finally, CTA is readily available at most hospitals, while RBC scintigraphy requires more time to be performed (radiotracer preparation, with 60 to 90 additional 
minutes needed for image acquisition after injection) and has more complicated logistics [123] (Table 13s).

\subsection{When should interventional radiology be used for the treatment of patients with lower gastro- intestinal bleeding?}

\section{RECOMMENDATION}

ESGE recommends that transcatheter arterial embolization should be reserved for the treatment of acute, potentially life-threatening, lower gastrointestinal bleeding either in hemodynamically unstable patients with active bleeding as demonstrated by computed tomography angiography or in patients with brisk and ongoing bleeding not amenable to or not effectively treated by endoscopic interventions.

Strong recommendation, low quality evidence.

\section{RECOMMENDATION}

ESGE recommends providing embolization within 60 minutes for a hemodynamically unstable patient, because time has been proven to be a significant factor influencing patient outcome.

Strong recommendation, low quality evidence.

Selective transcatheter endovascular therapy using microcatheters aims to decrease arterial perfusion to the bleeding site, ensuring super-selective embolization of arteries $<1 \mathrm{~mm}$. The choice of the embolizing agent, including absorbable gelatin sponges, cyanoacrylate glue, ethylene, or polyvinyl alcohol, and microcoils, is based upon operator experience and local availability.

Transcatheter arterial embolization as the first step in the management of acute LGIB should be reserved for patients demonstrating brisk and ongoing bleeding not amenable to or not effectively treated by endoscopic means. Hemodynamic instability, a drop in hemoglobin of $\geq 5 \mathrm{~g} / \mathrm{dL}$ from admission, and blood transfusion requirement of $\geq 5$ RBC units within 24 hours have been associated with the ability to locate the source of LGIB at selective mesenteric angiography [127].

A systematic review found that super-selective angiographic embolization achieved immediate hemostasis in $40 \%-100 \%$ of cases of diverticular bleeding, with rebleeding rates ranging from $0-50 \%$ [128]. The likelihood of identifying active bleeding was eight-fold higher if angiography was performed within 90 minutes of CTA, as shown in a retrospective study [129], and decreased when its performance following RBC scintigraphy was delayed [130]. Therefore, embolization should be provided within 60 minutes in hemodynamically unstable patients wherever an interventional radiology team is available. The risk of transcatheter embolization-induced bowel ischemia is $1 \%-4 \%$ and is related to the inability to achieve super-selective embolization [131, 132] (Table 14s).

\subsection{When should surgery be used as a diagnostic or therapeutic modality in patients with acute lower gastrointestinal bleeding?}

\section{RECOMMENDATION}

ESGE recommends that, except under exceptional circumstances, no patient should proceed to emergency exploratory laparotomy unless every effort has been made to locate the site of bleeding by endoscopic or radiological modalities.

Strong recommendation, low quality evidence.

\section{RECOMMENDATION}

ESGE recommends that surgery should only be undertaken if the lower gastrointestinal bleed is due to underlying pathology that is not amenable to endoscopic or radiological treatment, or if these modalities have failed.

Strong recommendation, low quality evidence.

No RCTs or non-randomized interventional studies have directly assessed laparotomy (open or minimally invasive) as the first diagnostic modality in comparison to radiological or endoscopic modalities in LGIB. Moreover, only a few prospective observational studies have assessed such management protocols in LGIB [49] (Table 15s). In the UK prospective audit, only six patients $(0.2 \%)$ underwent laparotomy for LGIB, with one of these following mesenteric artery embolization, and in only one case had laparotomy been the initial intervention [6]. In general, complications following emergency laparotomy for severe LGIB are common, including death $[6,133]$; therefore, surgical intervention should be undertaken only once all interventional radiologic and endoscopic measures have been exhausted. Even though the need for emergency laparotomy for LGIB is rare, there are indications where surgery may be justified (e.g. aortoenteric fistula or bleeding Meckel's diverticulum identified on Meckel's scan or at laparoscopy).

\section{Management of antithrombotic agents in patients with lower gastrointestinal bleeding}

Anticoagulant and antiplatelet use is reported in up to $30 \%$ of patients with acute LGIB, with $2 \%-5 \%$ of patients receiving complex antithrombotic therapies, including dual antiplatelet therapy (DAPT) or a combination of anticoagulant and antiplatelet agents $[6,134]$. The management of antithrombotic agents often requires a multidisciplinary approach that considers the severity of bleeding, the risk of rebleeding, and the patient's thrombotic risk. The ESGE recommendations in this guideline on the management of antithrombotic agents are in line with those reported in the ESGE guideline on non-variceal UGIB $[135,136]$, as the majority of evidence derives from UGIB studies. 


\subsection{Management of vitamin $\mathrm{K}$ antagonists in patients with lower gastrointestinal bleeding}

\section{RECOMMENDATION}

ESGE suggests not interrupting oral anticoagulation with vitamin $\mathrm{K}$ antagonists in patients presenting with minor self-limited bleeding (i. e. Oakland score $\leq 8$ ).

Weak recommendation, low quality evidence.

\section{RECOMMENDATION}

ESGE recommends withholding vitamin $\mathrm{K}$ antagonists in patients with major lower gastrointestinal bleeding and correcting their coagulopathy according to the severity of bleeding and their thrombotic risk. In patients with hemodynamic instability, we recommend administering intravenous vitamin $\mathrm{K}$ and four-factor prothrombin complex concentrate (PCC), or fresh frozen plasma if PCC is not available.

Strong recommendation, low quality evidence.

\section{RECOMMENDATION}

ESGE recommends restarting anticoagulant therapy following lower gastrointestinal bleeding in patients with an indication for long-term anticoagulation.

Strong recommendation, moderate quality evidence.

\section{RECOMMENDATION}

ESGE suggests restarting anticoagulation at the earliest from day 7 after the interruption of a vitamin $\mathrm{K}$ antagonist in patients at low thrombotic risk.

Weak recommendation, low quality evidence.

\section{RECOMMENDATION}

In those at high thrombotic risk, an earlier resumption of anticoagulation with heparin bridging, preferably within 72 hours, is recommended.

Strong recommendation, very low quality evidence.

In patients presenting with minor self-limited bleeding (Oakland score $\leq 8$ ), oral anticoagulation can be continued, while its discontinuation is the "standard of care" in patients with major LGIB. Vitamin K, prothrombin complex concentrate (PCC), or fresh frozen plasma (FFP) can be used for rapid correction of vitamin $\mathrm{K}$ antagonist-related coagulopathy, but the use of reversal agents (e.g. vitamin K) has been associated with thromboembolism in patients at high thrombotic risk (i.e. those with a mechanical heart valve) [137]. The correction of coagulopathy should not delay urgent therapeutic interventions [138], which can be safely performed at therapeutic levels of anticoagulation [34, 139].
Data from observational studies [140-143] and three metaanalyses [144-146] in the management of UGIB or GI bleeding highlight the net clinical benefit of restarting anticoagulation after the bleeding event, in lowering the risk of thromboembolism and death, despite increasing the risk of rebleeding (Table $16 \mathrm{~s}$ ). Because the thromboembolic risk increases over time, it is reasonable to restart warfarin as soon as possible from day 7 onward following its interruption. In patients at high thrombotic risk (prosthetic metal mitral heart valve, atrial fibrillation with prosthetic heart valve or mitral stenosis, or less than 3 months after venous thromboembolism) [147], cardiology societies recommend resumption of anticoagulation, with rapid titration of prophylactic doses of low molecular-weight heparin to therapeutic doses within 48-72 hours [148]. If the risk of resuming anticoagulation outweighs its benefits, consultation with a specialist (hematologist, neurologist, and/or cardiologist) is advised [148].

\subsection{Management of direct oral anticoagulants in patients with lower gastrointestinal bleeding}

\section{RECOMMENDATION}

ESGE suggests not interrupting direct oral anticoagulants in patients presenting with minor self-limited bleeding (i. e. Oakland score $\leq 8$ ).

Weak recommendation, low quality evidence.

\section{RECOMMENDATION}

ESGE recommends temporarily withholding direct oral anticoagulants at presentation in patients with major lower gastrointestinal bleeding.

Strong recommendation, low quality evidence.

\section{RECOMMENDATION}

ESGE suggests the use of reversal agents (idarucizumab in dabigatran patients and andexanet or four-factor PCC in anti-factor Xa-treated patients) in coordination/consultation with the local hematologist if bleeding is ongoing and/or there is recurrent hemodynamic instability. Weak recommendation, low quality evidence.

\section{RECOMMENDATION}

ESGE suggests restarting direct oral anticoagulant drug treatment following major lower gastrointestinal bleeding as soon as possible from day 7 .

Weak recommendation, low quality evidence.

Direct oral anticoagulants (DOACs) have a relatively short half-life, so that their anticoagulant effect rapidly wanes over 12-24 hours. Most cases of major LGIB can be managed by withholding the drug and waiting for the anticoagulant effects to dissipate. However, in hemodynamically unstable patients, 
acute reversal of anticoagulation may be required $[6,134,148]$. Vitamin K, FFP, and protamine administration are ineffective. Specific antagonists are available as first-line reversal agents in DOAC patients presenting with life-threatening/uncontrolled bleeding or requiring emergency surgery. Idarucizumab reverses dabigatran-related coagulopathy within a few minutes and lasts for about 24 hours in more than $98 \%$ of patients, and has a low thrombotic complication rate (6\% at 90 days) [149]. Andexanet alfa, an inactive form of factor-Xa that neutralizes circulating factor-Xa inhibitors, has recently been approved as an antidote to apixaban and rivaroxaban in patients with lifethreatening bleeding. Its clinical use is hindered by its limited availability, high cost, and safety concerns regarding its procoagulant effect [150]. Four-factor PCC at a fixed dose of 2000 IU may represent an alternative to andexanet alpha, with similar efficacy, yet with a lower thromboembolic risk [151153].

Data regarding the optimal timing of DOAC resumption following LGIB cessation are lacking, but similarly to warfarin, restarting the DOAC as soon as possible from day 7 onward after its interruption seems reasonable. DOAC resumption results in full re-anticoagulation within 2-4 hours, therefore early resumption should be undertaken with caution.

\subsection{Management of antiplatelet agents in patients with acute lower gastrointestinal bleeding}

\section{RECOMMENDATION}

ESGE does not recommend routine platelet transfusion for patients with lower gastrointestinal bleeding taking antiplatelet medications.

Strong recommendation, low quality evidence.

\section{RECOMMENDATION}

ESGE recommends withholding aspirin during the bleeding event in patients taking low dose aspirin for primary cardiovascular prevention and considering its permanent discontinuation unless clinically indicated after discussion with the referring specialist.

Strong recommendation, low quality evidence.

\section{RECOMMENDATION}

ESGE does not recommend withholding aspirin in patients taking low dose aspirin for secondary cardiovascular prevention. If withheld, low dose aspirin should be resumed, preferably within 5 days or even earlier if hemostasis is achieved or there is no further evidence of bleeding.

Strong recommendation, moderate quality evidence.

\section{RECOMMENDATION}

ESGE does not recommend routinely discontinuing dual antiplatelet therapy (low dose aspirin and a P2Y12 receptor antagonist) before cardiology consultation. Continuation of the aspirin is recommended, whereas the P2Y12 receptor antagonist can be continued or temporarily interrupted according to the severity of bleeding and the ischemic risk. If interrupted, the P2Y12 receptor antagonist should be restarted within 5 days, if still indicated. Strong recommendation, low quality evidence.

There is limited evidence to guide the management of antiplatelet therapy in LGIB (Table 17s). No drugs directly reversing platelet dysfunction exist and higher mortality, with a similar risk of rebleeding, has been reported in Gl bleeding patients on antiplatelet therapy receiving platelet transfusion in a retrospective study [154].

A retrospective study of 295 LGIB patients on aspirin showed that continuing aspirin was associated with an almost threefold increased risk of recurrent LGIB, but also with a 1.6-fold reduced risk of serious cardiovascular events and more than three-fold reduced risk of death within 5 years [155]. A prospective analysis ( $n=2528$ ) evaluated the short-term outcomes of antithrombotic drug interruption in patients hospitalized for LGIB. The in-hospital rebleeding rate was higher in patients on antiplatelet therapy, with most bleeding events occurring within 5 days from the time of admission. This incidence was comparable for patients who continued antiplatelet therapy throughout their hospitalization and those who had it witheld for fewer than 5 days [18]. Another cohort study, including 416 patients with gastrointestinal bleeding (162 LGIB), found no difference in rebleeding rates when the cutoff for resuming the antiplatelet agent was set at $\leq 7$ days [156].

According to these studies, continuing antiplatelet therapy during hospitalization may be appropriate in most patients with high cardiovascular risk, who cannot discontinue aspirin therapy, even for a short time. However, when temporary interruption is necessary (i.e. severe and persisting bleeding), antiplatelet therapy should be resumed within 5 days, after which time about $50 \%$ of circulating platelets are new and capable of producing thromboxane [157]. In patients at low thrombotic risk on primary cardiovascular prevention, discontinuation of aspirin at admission is recommended to reduce rebleeding without increasing the risk of cardiovascular events. Permanent discontinuation of aspirin should also be considered in liaison with the referring specialist.

Data regarding the management of LGIB patients taking DAPT are lacking. DAPT is mainly prescribed in patients undergoing percutaneous coronary intervention with stent placement. The management of such patients requires a careful assessment of their ischemic risk and a cardiology consultation is mandatory. DAPT is associated with a five-fold increased risk of in-hospital rebleeding, but not with bleeding-associated mortality $[18,158]$. However, discontinuing DAPT during the 
first 30 days following coronary stenting and during the first 90 days following acute coronary syndrome is associated with an increased risk of myocardial infarction and death [159]. Therefore, in patients at high ischemic risk, every effort should be made to continue antiplatelet therapy. Similarly to acute UGIB, in cases of severe LGIB, continuing aspirin as a single antiplatelet therapy appears to be reasonable, while withholding the non-aspirin antiplatelet agent for no more than 5-7 days [136]. A large systematic review examined the safety of shortterm antiplatelet discontinuation among patients with drugeluting stents and found very few cases of stent thrombosis within 10 days of thienopyridine interruption. Because the risk of rebleeding associated with DAPT is high, the required duration of DAPT should be reassessed after an LGIB event [160].

\subsection{Is there any role for antifibrinolytic medications in patients with acute lower gastrointestinal bleed- ing?}

\section{RECOMMENDATION}

ESGE does not recommend the use of tranexamic acid in patients with lower gastrointestinal bleeding.

Strong recommendation, high quality evidence.

In a large ( $\mathrm{n}=78291)$, nationwide, retrospective, propensity score-matched cohort study, tranexamic acid administration did not reduce in-hospital mortality among patients with diverticular bleeding [161]. Moreover, an RCT (the HALT-IT study) that evaluated 12009 patients with gastrointestinal bleeding (1328 LGIB) showed that intravenous tranexamic acid was associated with an increased risk of venous thromboembolic events, without reducing mortality [162].

\section{Disclaimer}

The legal disclaimer for ESGE guidelines [163] applies to this Guideline.

\section{Acknowledgments}

The authors are grateful to Dr. Andrew Veitch of the Department of Gastroenterology, Royal Wolverhampton Hospitals NHS Trust, Wolverhampton, UK and Dr. Lubna Kamani of the Department of Gastroenterology, Liaquat National Hospital, Karachi, Pakistan for their review of the manuscript.

\section{Competing interests}

M. Camus Duboc has provided consultancy to Boston Scientific (2017-2019) and Cook Medical (2019); she received editorial fees from HepatoGastroentérologie et Oncologie digestive (2020). I.M. Gralnek has provided consultancy to and been on the advisory board of MotusGI (2016 to present) and has provided consultancy to Boston Scientific (2020 to present) and Medtronic (2021). M. Hollenbach has provided consultancy and received an honorarium for expert group membership from Fuji (2020 to present). J.E. van Hooft has provided consultancy to Boston Scientific (2014 to 2017) and Olympus (2021), has received lecture fees from Medtronics (2014, 2015, and 2019) and Cook Medical (2019); her department has received research grants from Cook Medical (2014 to 2019) and Abbott (2014 to 2017). H. Awadie, D. Christodoulou, E. Fedorov, P. Gkolfakis, R.J. Guy, M. Ibrahim, G. Manes, Z. Neeman, K. Oakland, F. Radaelli, D. Regge, E. Rodriguez de Santiago, T.C. Tham, P. Thelin-Schmidt, and K. Triantafyllou declare that they have no conflict of interest.

\section{References}

[1] Guyatt GH, Oxman AD, Vist GE et al. GRADE: an emerging consensus on rating quality of evidence and strength of recommendations. BM] 2008; 336: 924-926

[2] Hassan C, Ponchon T, Bisschops R et al. European Society of Gastrointestinal Endoscopy (ESGE) Publications Policy - Update 2020. Endoscopy 2020; 52: 123-126

[3] Wong Kee Song LM, Baron TH. Endoscopic management of acute lower gastrointestinal bleeding. Am J Gastroenterol 2008; 103: 1881-1887

[4] Gralnek IM, Neeman Z, Strate LL. Acute lower gastrointestinal bleeding. NEJM 2017; 376: 1054-1063

[5] Strate LL, Ayanian JZ, Kotler G et al. Risk factors for mortality in lower intestinal bleeding. Clin Gastroenterol Hepatol 2008; 6: 1004-1010 quiz 955

[6] Oakland K, Guy R, Uberoi R et al. Acute lower Gl bleeding in the UK: patient characteristics, interventions and outcomes in the first nationwide audit. Gut 2018; 67: 654-662

[7] Jensen DM. The ins and outs of diverticular bleeding. Gastrointest Endosc 2012; 75: 388-391

[8] Ozdil B, Akkiz H, Sandikci M et al. Massive lower gastrointestinal hemorrhage secondary to rectal hemorrhoids in elderly patients receiving anticoagulant therapy: case series. Dig Dis Sci 2010; 55: 2693-2694

[9] Nagata N, Niikura R, Aoki T et al. Colonic diverticular hemorrhage associated with the use of nonsteroidal anti-inflammatory drugs, low-dose aspirin, antiplatelet drugs, and dual therapy. J Gastroenterol Hepatol 2014; 29: 1786-1793

[10] Taki M, Oshima T, Tozawa K et al. Analysis of risk factors for colonic diverticular bleeding and recurrence. Medicine (Baltimore) 2017; 96: e8090

[11] Yuhara H, Corley DA, Nakahara F et al. Aspirin and non-aspirin NSAIDs increase risk of colonic diverticular bleeding: a systematic review and meta-analysis. J Gastroenterol 2014; 49: 992-1000

[12] Cea Soriano L, Lanas A, Soriano-Gabarró M et al. Incidence of upper and lower gastrointestinal bleeding in new users of low-dose aspirin. Clin Gastroenterol Hepatol 2019; 17: 887-895.e6

[13] Chen W-C, Lin K-H, Huang Y-T et al. The risk of lower gastrointestina bleeding in low-dose aspirin users. Aliment Pharmacol Ther 2017; 45: $1542-1550$

[14] Miller CS, Dorreen A, Martel M et al. Risk of gastrointestinal bleeding in patients taking non-vitamin $\mathrm{K}$ antagonist oral anticoagulants: a systematic review and meta-analysis. Clin Gastroenterol Hepatol 2017; 15: 1674-1683.e3

[15] Strate LL, Orav EJ, Syngal S. Early predictors of severity in acute lower intestinal tract bleeding. Arch Intern Med 2003; 163: 838-843

[16] Sengupta N, Tapper EB. Derivation and internal validation of a clinical prediction tool for 30-day mortality in lower gastrointestinal bleeding. Am J Med 2017; 130: 601.e1-601.e8

[17] Kollef MH, Canfield DA, Zuckerman GR. Triage considerations for patients with acute gastrointestinal hemorrhage admitted to a medical intensive care unit. Crit Care Med 1995; 23: 1048-1054 
[18] Oakland K, Desborough M], Murphy MF et al. Rebleeding and mortality after lower gastrointestinal bleeding in patients taking antiplatelets or anticoagulants. Clin Gastroenterol Hepatol 2019; 17: 1276-1284.e3

[19] Laursen SB, Oakland K, Laine L et al. ABC score: a new risk score that accurately predicts mortality in acute upper and lower gastrointestinal bleeding: an international multicentre study. Gut 2021; 70: 707-716

[20] Aoki T, Nagata N, Shimbo T et al. Development and validation of a risk scoring system for severe acute lower gastrointestinal bleeding. Clin Gastroenterol Hepatol 2016; 14: 1562-1570.e2

[21] Smith SCL, Bazarova A, Ejenavi E et al. A multicentre development and validation study of a novel lower gastrointestinal bleeding score - The Birmingham Score. Int J Colorectal Dis 2020; 35: 285-293

[22] Quach DT, Nguyen NT-M, Vo UP-P et al. Development and validation of a scoring system to predict severe acute lower gastrointestinal bleeding in Vietnamese. Dig Dis Sci 2021; 66: 823-831

[23] Chong V, Hill AG, MacCormick AD. Accurate triage of lower gastrointestinal bleed (LGIB) - A cohort study. Int J Surg 2016; 25: 19-23

[24] Oakland K, Jairath V, Uberoi R et al. Derivation and validation of a novel risk score for safe discharge after acute lower gastrointestinal bleeding: a modelling study. Lancet Gastroenterol Hepatol 2017; 2: 635-643

[25] Hreinsson JP, Sigurdardottir R, Lund SH et al. The $\mathrm{SHA}_{2} \mathrm{PE}$ score: a new score for lower gastrointestinal bleeding that predicts low-risk of hospital-based intervention. Scand J Gastroenterol 2018; 53: 1484-1489

[26] Blatchford O, Murray WR, Blatchford M. A risk score to predict need for treatment for upper-gastrointestinal haemorrhage. Lancet 2000; 356: $1318-1321$

[27] Rockall TA, Logan RF, Devlin HB et al. Risk assessment after acute upper gastrointestinal haemorrhage. Gut 1996; 38: 316-321

[28] Saltzman JR, Tabak YP, Hyett BH et al. A simple risk score accurately predicts in-hospital mortality, length of stay, and cost in acute upper GI bleeding. Gastrointest Endosc 2011; 74: 1215-1224

[29] Tapaskar N, Jones B, Mei S et al. Comparison of clinical prediction tools and identification of risk factors for adverse outcomes in acute lower GI bleeding. Gastrointest Endosc 2019; 89: 1005-1013.e2

[30] Oakland K. Risk stratification in upper and upper and lower GI bleeding: Which scores should we use? Best Pract Res Clin Gastroenterol 2019; 42-43: 101613

[31] Kwak MS, Cha JM, Han Y] et al. The clinical outcomes of lower gastrointestinal bleeding are not better than those of upper gastrointestinal bleeding. J Korean Med Sci 2016; 31: 1611-1616

[32] Camus M, Jensen DM, Ohning GV et al. Comparison of three risk scores to predict outcomes of severe lower gastrointestinal bleeding. J Clin Gastroenterol 2016; 50: 52-58

[33] Oakland K, Kothiwale S, Forehand T et al. External validation of the Oakland score to assess safe hospital discharge among adult patients with acute lower gastrointestinal bleeding in the US. JAMA Netw Open 2020; 3: e209630

[34] Oakland K, Chadwick G, East JE et al. Diagnosis and management of acute lower gastrointestinal bleeding: guidelines from the British Society of Gastroenterology. Gut 2019; 68: 776-789

[35] National comparative audit of lower gastrointestinal bleeding and the use of blood: results from a national audit May 2016. Available at (Accessed 20.04.2021): https://www.acpgbi.org.uk/content/uploads/2016/07/National-Lower-Gastrointestinal-Bleed-Audit-Results-2016.pdf

[36] Strate LL, Gralnek IM. ACG Clinical Guideline: management of patients with acute lower gastrointestinal bleeding. Am J Gastroenterol 2016; 111: 755
[37] National Institute for Health and Care Excellence. Blood transfusion [NG24]. 2015: Available at (Accessed 20.04.2021): https://www. nice.org.uk/guidance/ng24/chapter/Recommendations\#red-bloodcells-2

[38] Mueller MM, van Remoortel H, Meybohm P et al. Patient blood management: recommendations from the 2018 Frankfurt Consensus Conference. JAMA 2019; 321: 983-997

[39] Villanueva C, Colomo A, Bosch A et al. Transfusion strategies for acute upper gastrointestinal bleeding. NEJM 2013; 368: 11-21

[40] Odutayo A, Desborough MJR, Trivella M et al. Restrictive versus liberal blood transfusion for gastrointestinal bleeding: a systematic review and meta-analysis of randomised controlled trials. Lancet Gastroenterol Hepatol 2017; 2: 354-360

[41] Wang J, Bao Y-X, Bai M et al. Restrictive vs liberal transfusion for upper gastrointestinal bleeding: a meta-analysis of randomized controlled trials. World J Gastroenterol 2013; 19: 6919-6927

[42] Kherad O, Restellini S, Martel M et al. Outcomes following restrictive or liberal red blood cell transfusion in patients with lower gastrointestinal bleeding. Aliment Pharmacol Ther 2019; 49: 919-925

[43] Holst LB, Petersen MW, Haase $N$ et al. Restrictive versus liberal transfusion strategy for red blood cell transfusion: systematic review of randomised trials with meta-analysis and trial sequential analysis. BMJ 2015; 350: h1354

[44] Trentino KM, Farmer SL, Sanfilippo FM et al. Systematic reviews and meta-analyses comparing mortality in restrictive and liberal haemoglobin thresholds for red cell transfusion: protocol for an overview of systematic reviews. BMJ Open 2019; 9: e029828

[45] Docherty AB, O’Donnell R, Brunskill $S$ et al. Effect of restrictive versus liberal transfusion strategies on outcomes in patients with cardiovascular disease in a non-cardiac surgery setting: systematic review and meta-analysis. BMJ 2016; 352: 11351

[46] Simon GI, Craswell A, Thom O et al. Outcomes of restrictive versus liberal transfusion strategies in older adults from nine randomised controlled trials: a systematic review and meta-analysis. Lancet Haematol 2017; 4: e465-e474

[47] Richter JM, Christensen MR, Kaplan LM et al. Effectiveness of current technology in the diagnosis and management of lower gastrointestinal hemorrhage. Gastrointest Endosc 1995; 41: 93-98

[48] García-Blázquez V, Vicente-Bártulos A, Olavarria-Delgado A et al. Accuracy of $\mathrm{CT}$ angiography in the diagnosis of acute gastrointestinal bleeding: systematic review and meta-analysis. Eur Radiol 2013; 23: $1181-1190$

[49] Oakland K, Isherwood J, Lahiff C et al. Diagnostic and therapeutic treatment modalities for acute lower gastrointestinal bleeding: a systematic review. Endosc Int Open 2017; 5: E959-E973

[50] Strate LL, Naumann CR. The role of colonoscopy and radiological procedures in the management of acute lower intestinal bleeding. Clin Gastroenterol Hepatol 2010; 8: 333-343 quiz e44

[51] Green BT, Rockey DC, Portwood G et al. Urgent colonoscopy for evaluation and management of acute lower gastrointestinal hemorrhage: a randomized controlled trial. Am J Gastroenterol 2005; 100 : 2395-2402

[52] Clerc D, Grass F, Schäfer M et al. Lower gastrointestinal bleeding computed tomographic angiography, colonoscopy or both? World ] Emerg Surg 2017; 12: 1

[53] Lee HS, Kang SH, Rou WS et al. Computed tomography versus lower endoscopy as initial diagnostic method for evaluating patients with hematochezia at emergency room. Medicine (Baltimore) 2020; 99: e20311

[54] Miyakuni Y, Nakajima M, Ohbe H et al. Angiography versus colonoscopy in patients with severe lower gastrointestinal bleeding: a nation-wide observational study. Acute Med Surg 2020; 7: e533 
[55] Kherad O, Restellini S, Almadi M et al. Systematic review with metaanalysis: limited benefits from early colonoscopy in acute lower gastrointestinal bleeding. Aliment Pharmacol Ther 2020; 52: 774788

[56] Anvari S, Lee Y, Yu J et al. Urgent versus standard colonoscopy for management of acute lower gastrointestinal bleeding: a systematic review and meta-analysis of randomized controlled trials. J Clin Gastroenterol 2020; 54: 493-502

[57] Tsay C, Shung D, Stemmer FrumentoK et al. Early colonoscopy does not improve outcomes of patients with lower gastrointestinal bleeding: systematic review of randomized trials. Clin Gastroenterol Hepatol 2020; 18: 1696-1703.e2

[58] Kouanda AM, Somsouk M, Sewell JL et al. Urgent colonoscopy in patients with lower $\mathrm{Gl}$ bleeding: a systematic review and metaanalysis. Gastrointest Endosc 2017; 86: 107-117.e1

[59] Seth A, Khan MA, Nollan R et al. Does urgent colonoscopy improve outcomes in the management of lower gastrointestinal bleeding? Am J Med Sci 2017; 353: 298-306

[60] Sengupta N, Tapper EB, Feuerstein JD. Early versus delayed colonoscopy in hospitalized patients with lower gastrointestinal bleeding: a meta-analysis. J Clin Gastroenterol 2017; 51: 352-359

[61] Roshan Afsharl, Sadr MS, Strate LL et al. The role of early colonoscopy in patients presenting with acute lower gastrointestinal bleeding: a systematic review and meta-analysis. Ther Adv Gastroenterol 2018; 11: $1756283 \times 18757184$

[62] Niikura R, Nagata N, Yamada A et al. Efficacy and safety of early vs elective colonoscopy for acute lower gastrointestinal bleeding. Gastroenterology 2020; 158: 168-175.e6

[63] Laine L, Shah A. Randomized trial of urgent vs. elective colonoscopy in patients hospitalized with lower GI bleeding. Am J Gastroenterol 2010; 105: 2636-2641 quiz 2642

[64] van Rongen I, Thomassen BJW, Perk LE. Early versus standard colonoscopy: a randomized controlled trial in patients with acute lower gastrointestinal bleeding: results of the BLEED study. J Clin Gastroenterol 2019; 53: 591-598

[65] Mosli M, Aldabbagh A, Aseeri $\mathrm{H}$ et al. The diagnostic yield of urgent colonoscopy in acute lower gastrointestinal bleeding. Acta Gastroenterol Belg 2020; 83: 265-270

[66] Nigam N, Ham SA, Sengupta N. Early colonoscopy for diverticular bleeding does not reduce risk of postdischarge recurrent bleeding: a propensity score matching analysis. Clin Gastroenterol Hepatol 2019; 17: 1105-1111.e1

[67] Saraireh H, Tayyem O, Siddiqui MT et al. Early colonoscopy in patients with acute diverticular bleeding is associated with improvement in healthcare-resource utilization. Gastroenterol Rep 2019; 7: $115-120$

[68] Wada M, Nishizawa T, Kato M et al. Colonic diverticular bleeding and predictors of the length of hospitalization: An observational study. J Gastroenterol Hepatol 2019; 34: 1351-1356

[69] Kim JH, Kim JH, Chun ] et al. Early versus late bedside endoscopy for gastrointestinal bleeding in critically ill patients. Korean J Intern Med 2018; 33: 304-312

[70] Devani K, Bhaumik P, Dhruvil R et al. Trends of early colonoscopy and their outcomes in patients admitted with acute lower gastrointestinal bleeding: Fellows-in-Training Award (GI bleeding category). Am J Gastroenterol 2018; 113: S304-S305

[71] El Douaihy Y, Nassani N, Al Moussawi H et al. Outcomes of early versus late colonoscopy in acute lower gastrointestinal bleeding: A single center experience. Am J Gastroenterol 2017; 112: S1474

[72] Winn J, Abdul-Kafi O, Rao $S$ et al. Optimal timing of endoscopy for lower gastrointestinal bleeding. Am J Gastroenterol 2016; 111: S153-S154
[73] Hassan M, Meighani A, Rao B et al. Early versus late colonoscopy in patients presenting with diverticular bleeds: A single center experience. Gastrointest Endosc 2016; 83: AB280

[74] Nagata N, Niikura R, Sakurai T et al. Safety and effectiveness of early colonoscopy in management of acute lower gastrointestinal bleeding on the basis of propensity score matching analysis. Clin Gastroenterol Hepatol 2016; 14: 558-564

[75] Niikura R, Nagata N, Aoki T et al. Predictors for identification of stigmata of recent hemorrhage on colonic diverticula in lower gastrointestinal bleeding. J Clin Gastroenterol 2015; 49: e24-e30

[76] Albeldawi M, Ha D, Mehta P et al. Utility of urgent colonoscopy in acute lower gastro-intestinal bleeding: a single-center experience. Gastroenterol Rep 2014; 2: 300-305

[77] Navaneethan U, Njei B, Venkatesh PGK et al. Timing of colonoscopy and outcomes in patients with lower $\mathrm{Gl}$ bleeding: a nationwide population-based study. Gastrointest Endosc 2014; 79: 297-306. e12

[78] Schmulewitz N, Fisher DA, Rockey DC. Early colonoscopy for acute lower GI bleeding predicts shorter hospital stay: a retrospective study of experience in a single center. Gastrointest Endosc 2003; 58: 841-846

[79] Strate LL, Syngal S. Timing of colonoscopy: impact on length of hospital stay in patients with acute lower intestinal bleeding. Am J Gastroenterol 2003; 98: 317-322

[80] Rodríguez-Moranta F, Berrozpe A, Botargues JM et al. Colonoscopy delay in lower gastrointestinal bleeding: influence on diagnostic accuracy, endoscopic therapy and hospital stay. Gastrointest Endosc 2007; 65: AB261

[81] Repaka A, Atkinson MR, Faulx AL et al. Immediate unprepared hydroflush colonoscopy for severe lower GI bleeding: a feasibility study. Gastrointest Endosc 2012; 76: 367-373

[82] Gül Utku Ö, Karatay E. Immediate unprepared polyethylene glycolflush colonoscopy in elderly patients with severe lower gastrointestinal bleeding. Geriatr Gerontol Int 2020; 20: 559-563

[83] Ohyama T, Sakurai Y, Ito M et al. Analysis of urgent colonoscopy for lower gastrointestinal tract bleeding. Digestion 2000; 61: 189-192

[84] Akhtar AJ. Lower gastrointestinal hemorrhage in African-American and Hispanic elderly patients. Ethn Dis 2002; 12: 379-382

[85] Jensen DM, Machicado GA. Diagnosis and treatment of severe hematochezia. The role of urgent colonoscopy after purge. Gastroenterology 1988; 95: 1569-1574

[86] Srygley FD, Gerardo C], Tran T et al. Does this patient have a severe upper gastrointestinal bleed? JAMA 2012; 307: 1072-1079

[87] Jensen DM, Machicado GA, Rome J et al. Urgent colonoscopy for the diagnosis and treatment of severe diverticular hemorrhage. NEJM 2000; 342: 78-82

[88] Pontone S, Palma R, Panetta C et al. Polyethylene glycol-based bowel preparation before colonoscopy for selected inpatients: A pilot study. J Dig Dis 2018; 19: 40-47

[89] Soriani P, Hassan C, Ottaviani L et al. Efficacy of rapid bowel preparation with new $1 \mathrm{~L}$ polyethylene glycol ascorbate solution in severe acute lower GI bleeding. VideoGIE 2020; 5: 114-115

[90] Malik A, Inayat F, Goraya MHN et al. Severe acute colonic diverticular bleeding: the efficacy of rapid bowel preparation with $1 \mathrm{~L}$ polyethylene glycol ascorbate solution and direct endoscopic hemoclipping for successful hemostasis. J Investig Med High Impact Case Rep 2021; 9: 2324709621994383

[91] Utku ÖG, Karatay E. Immediate unprepared polyethylene glycolflush colonoscopy in elderly patients with severe lower gastrointestinal bleeding. Geriatr Gerontol Int 2020; 20: 559-563 
[92] Niikura R, Nagata N, Shimbo T et al. Adverse events during bowel preparation and colonoscopy in patients with acute lower gastrointestinal bleeding compared with elective non-gastrointestinal bleeding. PLOS ONE 2015; 10: 1-12

[93] Bloomfeld RS, Rockey DC, Shetzline MA. Endoscopic therapy of acute diverticular hemorrhage. Am J Gastroenterol 2001; 96: 23672372

[94] Okamoto N, Tominaga N, Sakata Y et al. Lower rebleeding rate after endoscopic band ligation than endoscopic clipping of the same colonic diverticular hemorrhagic lesion: a historical multicenter trial in Saga, Japan. Intern Med 2019; 58: 633-638

[95] Ishii N, Omata F, Nagata N et al. Effectiveness of endoscopic treatments for colonic diverticular bleeding. Gastrointest Endosc 2018; 87: 58-66

[96] Tsuruoka N, Takedomi H, Sakata Y et al. Recent trends in treatment for colonic diverticular bleeding in Japan. Digestion 2020; 101: 1217

[97] Witte JT. Band ligation for colonic bleeding: modification of multiband ligating devices for use with a colonoscope. Gastrointest Endosc 2000; 52: 762-765

[98] Farrell J], Graeme-Cook F, Kelsey PB. Treatment of bleeding colonic diverticula by endoscopic band ligation: an in-vivo and ex-vivo pilot study. Endoscopy 2003; 35: 823-829

[99] Marques S, Barreiro P, Chagas C. Endoscopic band ligation: a safe and effective treatment for active diverticular bleeding. ACG Case Rep J 2016; 3: 77-78

[100] Barker KB, Arnold HL, Fillman EP et al. Safety of band ligator use in the small bowel and the colon. Gastrointest Endosc 2005; 62: 224227

[101] Campo R, Brullet E, Montané JM et al. Elastic band ligation in the bowel: is it really safe? Gastrointest Endosc 1998; 47: 105-106

[102] Takahashi S, Inaba T, Tanaka N. Delayed perforation after endoscopic band ligation for treatment of colonic diverticular bleeding. Dig Endosc 2016; 28: 484

[103] Sato Y, Yasuda H, Fukuoka A et al. Delayed perforation after endoscopic band ligation for colonic diverticular hemorrhage. Clin J Gastroenterol 2020; 13: 6-10

[104] Akutsu D, Narasaka T, Wakayama M et al. Endoscopic detachable snare ligation: a new treatment method for colonic diverticular hemorrhage. Endoscopy 2015; 47: 1039-1042

[105] Prei JC, Barmeyer C, Bürgel N et al. EndoClot polysaccharide hemostatic system in nonvariceal gastrointestinal bleeding: results of a prospective multicenter observational pilot study. J Clin Gastroenterol 2016; 50: e95-e100

[106] Chen Y-I, Barkun AN. Hemostatic powders in gastrointestinal bleeding: a systematic review. Gastrointest Endosc Clin N Am 2015; 25: 535-552

[107] Ng JL, Marican M, Mathew R. Topical haemostatic powder as a novel endoscopic therapy for severe colonic diverticular bleeding. ANZ J Surg 2019; 89: E56-E60

[108] Holster IL, Brullet E, Kuipers EJ et al. Hemospray treatment is effective for lower gastrointestinal bleeding. Endoscopy 2014; 46: 75-78

[109] Olmos JA, Marcolongo M, Pogorelsky V et al. Long-term outcome of argon plasma ablation therapy for bleeding in 100 consecutive patients with colonic angiodysplasia. Dis Colon Rectum 2006; 49: $1507-1516$

[110] Kwan V, Bourke MJ, Williams S] et al. Argon plasma coagulation in the management of symptomatic gastrointestinal vascular lesions: experience in 100 consecutive patients with long-term follow-up. Am J Gastroenterol 2006; 101: 58-63

[111] Suzuki N, Arebi N, Saunders BP. A novel method of treating colonic angiodysplasia. Gastrointest Endosc 2006; 64: 424-427
[112] Ramadani A, Jovanovska RP, Trajkovska M et al. Comparison of argon plasma coagulation and injection therapy with adrenalin and polidocanol in the management of bleeding angiodysplasia in upper gastrointestinal tract. Pril (Makedon Akad Nauk Umet Odd Med Nauki) 2018; 39: 63-68

[113] Gutta A, Gromski MA. Endoscopic management of post-polypectomy bleeding. Clin Endosc 2020; 53: 302-310

[114] Guo S-B, Gong A-X, Leng J et al. Application of endoscopic hemoclips for nonvariceal bleeding in the upper gastrointestinal tract. World J Gastroenterol 2009; 15: 4322-4326

[115] Binmoeller KF, Thonke F, Soehendra N. Endoscopic hemoclip treatment for gastrointestinal bleeding. Endoscopy 1993; 25: 167-170

[116] Hong SP. How do I manage post-polypectomy bleeding? Clin Endosc 2012; 45: 282-284

[117] Hookey L, Barkun A, Sultanian R et al. Successful hemostasis of active lower $\mathrm{Gl}$ bleeding using a hemostatic powder as monotherapy, combination therapy, or rescue therapy. Gastrointest Endosc 2019; 89: 865-871

[118] Kennedy DW, Laing C], Tseng LH et al. Detection of active gastrointestinal hemorrhage with CT angiography: a 4(1/2)-year retrospective review. J Vasc Interv Radiol 2010; 21: 848-855

[119] Ren J-Z, Zhang M-F, Rong A-M et al. Lower gastrointestinal bleeding: role of 64-row computed tomographic angiography in diagnosis and therapeutic planning. World J Gastroenterol 2015; 21: 4030-4037

[120] Foley PT, Ganeshan A, Anthony S et al. Multi-detector CT angiography for lower gastrointestinal bleeding: Can it select patients for endovascular intervention? J Med Imaging Radiat Oncol 2010; 54: 9-16

[121] Nagata N, Niikura R, Aoki T et al. Role of urgent contrast-enhanced multidetector computed tomography for acute lower gastrointestinal bleeding in patients undergoing early colonoscopy. J Gastroenterol 2015; 50: 1162-1172

[122] Nakatsu S, Yasuda H, Maehata T et al. Urgent computed tomography for determining the optimal timing of colonoscopy in patients with acute lower gastrointestinal bleeding. Intern Med 2015; 54: 553558

[123] Jacovides CL, Nadolski G, Allen SR et al. Arteriography for lower gastrointestinal hemorrhage: role of preceding abdominal computed tomographic angiogram in diagnosis and localization. JAMA Surg 2015; 150: 650-656

[124] Zink SI, Ohki SK, Stein B et al. Noninvasive evaluation of active lower gastrointestinal bleeding: comparison between contrast-enhanced MDCT and 99mTc-labeled RBC scintigraphy. AJR Am J Roentgenol 2008; 191: 1107-1114

[125] Speir EJ, Newsome JM, Bercu ZL et al. Correlation of CT angiography and $99 m$ technetium-labeled red blood cell scintigraphy to catheter angiography for lower gastrointestinal bleeding: a single-institution experience. J Vasc Interv Radiol 2019; 30: 1725-1732.e7

[126] Feuerstein JD, Ketwaroo G, Tewani SK et al. Localizing acute lower gastrointestinal hemorrhage: $\mathrm{CT}$ angiography versus tagged RBC scintigraphy. AJR Am J Roentgenol 2016; 207: 578-584

[127] Abbas SM, Bissett IP, Holden A et al. Clinical variables associated with positive angiographic localization of lower gastrointestinal bleeding. ANZ J Surg 2005; 75: 953-957

[128] Khanna A, Ognibene S], Koniaris LG. Embolization as first-line therapy for diverticulosis-related massive lower gastrointestinal bleeding: evidence from a meta-analysis. J Gastrointest Surg 2005; 9: 343-352

[129] Koh FH, Soong J, Lieske B et al. Does the timing of an invasive mesenteric angiography following a positive $\mathrm{CT}$ mesenteric angiography make a difference? Int J Colorectal Dis 2015; 30: 57-61 
[130] Chung M, Dubel G], Noto RB et al. Acute lower gastrointestinal bleeding: temporal factors associated with positive findings on catheter angiography after (99m)Tc-labeled RBC scanning. AJR Am J Roentgenol 2016; 207: 170-176

[131] Ali M, UI Haq T, Salam B et al. Treatment of nonvariceal gastrointestinal hemorrhage by transcatheter embolization. Radiol Res Pract 2013; 2013: 604328

[132] Yata S, Ihaya T, Kaminou T et al. Transcatheter arterial embolization of acute arterial bleeding in the upper and lower gastrointestinal tract with N-butyl-2-cyanoacrylate. J Vasc Interv Radiol 2013; 24: 422-431

[133] Czymek R, Kempf A, Roblick U et al. Factors predicting the postoperative outcome of lower gastrointestinal hemorrhage. Int J Colorectal Dis 2009; 24: 983-988

[134] Radaelli F, Frazzoni L, Repici A et al. Clinical management and patient outcomes of acute lower gastrointestinal bleeding. A multicenter, prospective, cohort study. Dig Liver Dis 2021: doi:10.1016/j. dld.2021.01.002

[135] Gralnek IM, Dumonceau J-M, Kuipers EJ et al. Diagnosis and management of nonvariceal upper gastrointestinal hemorrhage: European Society of Gastrointestinal Endoscopy (ESGE) Guideline. Endoscopy 2015; 47: a1-a46

[136] Gralnek IM, Stanley AJ, Morris AJ et al. Endoscopic diagnosis and management of nonvariceal upper gastrointestinal hemorrhage (NVUGIH): European Society of Gastrointestinal Endoscopy (ESGE) Guideline - Update 2021. Endoscopy 2021; 53: 300-332

[137] Nagata N, Sakurai T, Moriyasu S et al. Impact of INR monitoring, reversal agent use, heparin bridging, and anticoagulant interruption on rebleeding and thromboembolism in acute gastrointestinal bleeding. PloS One 2017; 12: e0183423

[138] Choudari CP, Rajgopal C, Palmer KR. Acute gastrointestinal haemorrhage in anticoagulated patients: diagnoses and response to endoscopic treatment. Gut 1994; 35: 464-466

[139] Jamula E, Lloyd NS, Schwalm J-D et al. Safety of uninterrupted anticoagulation in patients requiring elective coronary angiography with or without percutaneous coronary intervention: a systematic review and metaanalysis. Chest 2010; 138: 840-847

[140] Qureshi W, Mittal C, Patsias I et al. Restarting anticoagulation and outcomes after major gastrointestinal bleeding in atrial fibrillation. Am J Cardiol 2014; 113: 662-668

[141] Sengupta N, Feuerstein JD, Patwardhan VR et al. The risks of thromboembolism vs. recurrent gastrointestinal bleeding after interruption of systemic anticoagulation in hospitalized inpatients with gastrointestinal bleeding: a prospective study. Am J Gastroenterol 2015; 110: 328-335

[142] Staerk L, Lip GYH, Olesen JB et al. Stroke and recurrent haemorrhage associated with antithrombotic treatment after gastrointestinal bleeding in patients with atrial fibrillation: nationwide cohort study. BMJ 2015; 351: h5876

[143] Witt DM, Delate T, Garcia DA et al. Risk of thromboembolism, recurrent hemorrhage, and death after warfarin therapy interruption for gastrointestinal tract bleeding. Arch Intern Med 2012; 172: 1484-1491

[144] Chai-Adisaksopha C, lorio A, Hillis C et al. Warfarin resumption following anticoagulant-associated intracranial hemorrhage: A systematic review and meta-analysis. Thromb Res 2017; 160: 97-104

[145] Little D, Chai-Adisaksopha C, Hillis C et al. Resumption of anticoagulant therapy after anticoagulant-related gastrointestinal bleeding: A systematic review and meta-analysis. Thromb Res 2019; 175: 102-109

[146] Tapaskar N, Pang A, Werner DA et al. Resuming anticoagulation following hospitalization for gastrointestinal bleeding is associated with reduced thromboembolic events and improved mortality: results from a systematic review and meta-analysis. Dig Dis Sci 2021; 66: 554-566

[147] Veitch AM, Vanbiervliet G, Gershlick AH et al. Endoscopy in patients on antiplatelet or anticoagulant therapy, including direct oral anticoagulants: British Society of Gastroenterology (BSG) and European Society of Gastrointestinal Endoscopy (ESGE) guidelines. Endoscopy 2016; 48: 385-402

[148] Steffel J, Verhamme P, Potpara TS et al. The 2018 European Heart Rhythm Association Practical Guide on the use of non-vitamin K antagonist oral anticoagulants in patients with atrial fibrillation. Eur Heart J 2018; 39: 1330-1393

[149] Pollack CV, Reilly PA, van Ryn J et al. Idarucizumab for dabigatran reversal - full cohort analysis. NEJM 2017; 377: 431-441

[150] Connolly S], Crowther M, Eikelboom JW et al. Full study report of andexanet alfa for bleeding associated with factor Xa inhibitors. NEJM 2019; 380: 1326-1335

[151] Majeed A, Ågren A, Holmström M et al. Management of rivaroxabanor apixaban-associated major bleeding with prothrombin complex concentrates: a cohort study. Blood 2017; 130: 1706-1712

[152] Piran S, Khatib R, Schulman S et al. Management of direct factor Xa inhibitor-related major bleeding with prothrombin complex concentrate: a meta-analysis. Blood Adv 2019; 3: 158-167

[153] Smith MN, Deloney L, Carter C et al. Safety, efficacy, and cost of four-factor prothrombin complex concentrate (4F-PCC) in patients with factor $\mathrm{Xa}$ inhibitor-related bleeding: a retrospective study. J Thromb Thrombolysis 2019; 48: 250-255

[154] Zakko L, Rustagi T, Douglas M et al. No benefit from platelet transfusion for gastrointestinal bleeding in patients taking antiplatelet agents. Clin Gastroenterol Hepatol 2017; 15: 46-52

[155] Chan FKL, Leung KiE-L, Wong GLH et al. Risks of bleeding recurrence and cardiovascular events with continued aspirin use after lower gastrointestinal hemorrhage. Gastroenterology 2016; 151: 271-277

[156] Sostres C, Marcén B, Laredo V et al. Risk of rebleeding, vascular events and death after gastrointestinal bleeding in anticoagulant and/or antiplatelet users. Aliment Pharmacol Ther 2019; 50: 919929

[157] Koupenova M, Kehrel BE, Corkrey HA et al. Thrombosis and platelets: an update. Eur Heart J 2017; 38: 785-791

[158] Patel P, Nigam N, Sengupta N. Lower gastrointestinal bleeding in patients with coronary artery disease on antithrombotics and subsequent mortality risk. J Gastroenterol Hepatol 2018; 33: 11851191

[159] Eisenberg MJ, Richard PR, Libersan D et al. Safety of short-term discontinuation of antiplatelet therapy in patients with drug-eluting stents. Circulation 2009; 119: 1634-1642

[160] Valgimigli M, Bueno H, Byrne RA et al. 2017 ESC focused update on dual antiplatelet therapy in coronary artery disease developed in collaboration with EACTS: The Task Force for dual antiplatelet therapy in coronary artery disease of the European Society of Cardiology (ESC) and of the European Association for Cardio-Thoracic Surgery (EACTS). Eur Heart J 2018; 39: 213-260

[161] Miyamoto $\mathrm{Y}$, Ohbe $\mathrm{H}$, Ishimaru $\mathrm{M}$ et al. Effect of tranexamic acid in patients with colonic diverticular bleeding: A nationwide inpatient database study. J Gastroenterol Hepatol 2021; 36: 999-1005

[162] HALT-IT Trial Collaborators. Effects of a high-dose 24-h infusion of tranexamic acid on death and thromboembolic events in patients with acute gastrointestinal bleeding (HALT-IT): an international randomised, double-blind, placebo-controlled trial. Lancet 2020; 395: 1927-1936

[163] Hassan C, Ponchon T, Bisschops R et al. European Society of Gastrointestinal Endoscopy (ESGE) Publications Policy - Update 2020. Endoscopy 2020; 52: 123-126 